\title{
A RBFNN \& GACMOO-Based Working State Optimization Control Study on Heavy-Duty Diesel Engine Working in Plateau Environment
}

\author{
Yi Dong ${ }^{1}$, Jianmin Liu ${ }^{1}$, Yanbin Liu ${ }^{1, *}$, Xinyong Qiao ${ }^{1}$, Xiaoming Zhang ${ }^{1}$, Ying Jin ${ }^{1}$, \\ Shaoliang Zhang ${ }^{1}$, Tianqi Wang ${ }^{1}$ and Qi Kang ${ }^{2}$ \\ 1 Vehicle Engineering Department, Army Academy of Armored Forces, Beijing 100072, China; \\ 13391567396@163.com (Y.D.); Liujianmin@163.com (J.L.); aafeqxy@sina.com (X.Q.); true@163.com (X.Z.); \\ Jinying@163.com (Y.J.); Zhangsl@163.com (S.Z.); Wangtianqi@163.com (T.W.) \\ 2 China Satellite Maritime Tracking and Controlling Department, Wuxi 214431, China; kangqi@163.com \\ * Correspondence: yanbin.liu@xecaturbo.cn; Tel.: +86-185-1458-6180
}

Received: 15 December 2019; Accepted: 2 January 2020; Published: 6 January 2020

\begin{abstract}
In order to solve issues concerning performance induction and in-cylinder heat accumulation of a certain heavy-duty diesel engine in a plateau environment, working state parameters and performance indexes of diesel engine are calculated and optimized using the method of artificial neural network and genetic algorithm cycle multi-objective optimization. First, with an established diesel engine simulation model and an orthogonal experimental method, the influence rule of five performance indexes affected by five working state parameters are calculated and analyzed. Results indicate the first four of five working state parameters have a more prominent influence on those five performance indexes. Subsequently, further calculation generates correspondences among four working state parameters and five performance indexes with the method of radial basis function neural network. The predicted value of the trained neural network matches well with the original one. The approach can fulfill serialization of discrete working state parameters and performance indexes to facilitate subsequent analysis and optimization. Next, we came up with a new algorithm named RBFNN \& GACMOO, which can calculate the optimal working state parameters and the corresponding performance indexes of the diesel engine working at $3700 \mathrm{~m}$ altitude. At last, the bench test of the diesel engine in a plateau environment is employed to verify accuracy of the optimized results and the effectiveness of the algorithm. The research first combined the method of artificial neural network and genetic algorithm to specify the optimal working state parameters of the diesel engine at high altitudes by focusing on engine power, torque and heat dissipation, which is of great significance for improving both performance and working reliability of heavy-duty diesel engine working in plateau environment.
\end{abstract}

Keywords: diesel engine; plateau; radial basis function neural network; genetic algorithm; multi-objective optimization

\section{Introduction}

Compared with plain, plateau features lower atmospheric pressure and air density. Consequently, when working in a plateau environment, the diesel engine becomes troubled with such problems as excessively high exhaust temperature, black smoke, overheating key parts, power performance, and fuel economy reduction, which severely restrain performance of diesel engine, especially the heavy-duty ones. This also produces a serious adverse effect on national economy, industrial production at plateau. Since air in plateau environment remains thin, quantity of air entering cylinder reduces. Air pressure and density in combustion chamber are lowered when piston is compressed to top dead 
center (TDC), impairing both quality and temperature of air-fuel mixture so that a combustion lag or incomplete combustion appears. The final consequence is diesel engine fail to operate normally. In view of such phenomenon, it remains an important issue in this field to make a detailed study of matching and controlling strategies among intake, exhaust and oil supply in diesel engine working in plateau environment.

In view of dramatic performance reduction of diesel engine working in plateau environment, scholars have made a lot of useful explorations. Zhengxia Zhu et al., [1] optimized fuel-injection quantity under rated conditions in the plateau environment using a genetic algorithm with penalty function and diesel engine operation process simulation model, and their results indicate post-optimization power of engine rises by $22.7 \%$, efficiency of engine rises by $6.4 \%$. Huaiqing Zhong et al. [2] established operation simulation model of certain diesel engine through such software as BOOST, and verified the model with experimental data. Later, they proposed some plateau-specific optimizing and improving measures such as "replacing with mass flow supercharger", "raising compression ratio" and "enlarging fuel supply advance angle" on the basis of this simulation model. To cope with power performance reduction and combustion deterioration of certain heavy-duty diesel engine in plateau environment, Piqiang Tan et al., [3] experimented with combined parameters of different compression ratio, turbine ratio and oil atomizer nozzle diameter, and finally determined three optimal plans that could improve power, fuel economy, and emission performance of diesel engine working in plateau environment. Hong Zhang et al., [4] studied the performance of compressor of diesel engine working at plateau, they use the simulation model of diesel engine to calculate the effect of environment parameter and key parameter of compressor to the performance of compressor. At last, they obtained the key parameters that affect the compressor's performance the most. The results of their study can help to improve the performance reduction condition of compressor and engine working at plateau. Meng Xia et al., [5] using the genetic algorithm and GT-POWER simulation model to improve the performance of $6 \mathrm{~V}$ diesel engine, which works at plateau, show that the fuel consumption deterioration is restricted minus $5 \%$ and the torque is increased by $9 \%$. There are also other researches focusing on combustion [6], emission [7], blend oil [8], performance optimization [9], spray pattern [10] of diesel engine.

With the emerging of artificial intelligence (AI) and machine learning, many scholars have applied it to calculate, predict and optimize diesel engine's performance. In the hope of figuring out the optimum ratio of biodiesel, Ka In Wong et al., [11] created a simulation model of diesel engine using experimental data, extreme learning machine (ELM), and least squares support vector machine (LS-SVM), then they compared and analyzed the strengths and weaknesses of two algorithms (simulated annealing algorithm and particle swarm optimization algorithm) in finding the optimum biodiesel proportion using the simulation model. Jinxing Zhao et al., [12] computed and analyzed optimal fuel economy of an Atkinson cycle engine with approach of artificial neural network (ANN). Based on one-dimensional simulation model and genetic algorithm (GA), the author conducted an optimization study on fuel economy of diesel engine operating under part load. As such, parameters as inlet valve closing timing, exhaust valve opening timing, electronic throttle control part, electric spark timing and air-fuel ratio were optimized, and fuel economy of diesel engine got elevated by $7.67 \%$ after optimization. HeeCheong Yoo et al., [13] studied the effects of electric supercharger and exhaust gas recirculation to the emissions and fuel efficiency of the diesel engine; authors also used the method of design of experiment and plotted the response surface of the BSFC. At last, they get the optimal Pareto fronts. Marco Bietresato et al., [14] used the response surface methodology (RSM) to analyze the correspondence relationship between the performance of internal combustion engine and biofuel blends condition. According to the result, this method shows good prediction capabilities and blend composition can be applied to accurately predict the performance of the engine. Bahman Najafi et al. [15] used the intelligent artificial neural network and RSM to get the optimal fuel blend of the diesel engine, the calculation and experiment results show that optimum values of exergy and energy efficiencies are in the range of $25-30 \%$ of full load. There are also some other algorithms applied to this field, e.g., support vector machine (SVM) [16], artificial bee colony (ABC) [17], energy blockchain 
network (EBN) [18], Multiple Utility Problem Table (MUPT) [19], quasi-optimal (QO) [20] algorithm and so on.

When working at plateau, what diesel engine faces is not only deteriorating combustion condition in cylinder but also severe deterioration of cooling radiator capacity of dynamic system [21]. Deterioration of in-cylinder combustion and cooling capacity make some high-temperature parts in cylinder like piston, cylinder cover and cylinder gasket accumulate excessive heat, which will lead these parts subjected to fatigue damage and failure [22]. However, there is a paucity of computation focusing on in-cylinder heat accumulation and dissipation among studies on diesel engine working in plateau environment [23]. In addition, several existed researches are limited to the area of combustion and emission [24]. In-cylinder heat dissipation affects thermal state of high-temperature parts and has further great effects on parts' stress condition and whole machine's reliability [25]. Therefore, it is necessary to research the performance and in-cylinder heat accumulation and dissipation of diesel engine working at plateau. There are some other researchers studying diesel engine working at plateau, the main focus of these articles are combustion and emission characteristics [26], effects of altitudes [27], two-stage turbocharging system [28], and altitude adaptability of turbocharging [29].

To provide a solution to aforesaid questions, this paper, based on orthogonal experiment design, radial basis function neural network and genetic algorithm, calculates and analyzes the optimal working state parameters of diesel engine at high altitude by focusing on three performance indexes such as power, torque, and in-cylinder heat dissipation. This approach is capable to determine the optimal working state parameters of diesel engine working at plateau in an efficient and accurate way, so as to maximize the overall engine's performance and bring down the thermal load of high-temperature parts. The work in this paper is mainly composed of the following parts. In the first place, a simulation model of diesel engine is established for computing and analyzing the effect of five working state parameters of diesel engine on its performance indexes in combination with orthogonal experiment. According to the results, four parameters are selected for subsequent calculation and analysis. Then, radial basis function neural network and calculation-derived data are used to exert learning and training on correspondences between four parameters and five indexes, and the results are verified using part of calculation-derived data. Through radial basis function neural network, discrete input parameters and output indexes are converted to continuous values to facilitate subsequent calculation and analysis. Next, genetic algorithm is employed together with radial basis function neural network to calculate the optimal working state parameters of diesel engine at $3700 \mathrm{~m}$ altitude and $2000 \mathrm{rpm}$. At last, the data from the bench test verify the accuracy of calculation outcome and the effectiveness of algorithms.

\section{Establishment and Verification of Diesel Engine Simulation Model}

\subsection{Model Establishment}

In this paper, certain heavy-duty diesel engine is selected as the research subject. Its structural parameters and performance indexes at plain condition are listed in Table 1. The simulation model of the diesel engine's left part is established with the software of GT-POWER, as shown in Figure 1. The main components of the model include the inlet and exhaust pipes, compressor, inlet and outlet value, oil injector, cylinders and turbine. The heat transfer model in cylinder is set as Woschni model, combustion model is set as turbulent flame model, and the oil injection model is set as InjAF-Ratio-Conn injection model. In the simulation model, we simplified the inlet and outlet pipes into rough cylindrical pipes.

Table 1. Structural parameters and performance indexes of diesel engine.

\begin{tabular}{cc}
\hline Parameters & Values \\
\hline Structure & Turbocharging, four stroke \\
Cylinders & 12 cylinders, V-type \\
Cylinder diameter/length of stroke $(\mathrm{mm})$ & $150 / 180$ \\
\hline
\end{tabular}


Table 1. Cont.

\begin{tabular}{cc}
\hline Parameters & Values \\
\hline Compression ratio/total displacement $(\mathrm{L})$ & $13.5: 1 / 38.8$ \\
Length of connecting rod $(\mathrm{mm})$ & 320 \\
Rated power $(\mathrm{kW})$ & 537 \\
Rated speed $(\mathrm{rpm})$ & 2000 \\
Maximum torque $(\mathrm{N} \cdot \mathrm{m})$ & 2991 \\
Speed at maximum torque $(\mathrm{rpm})$ & 1400 \\
\hline
\end{tabular}

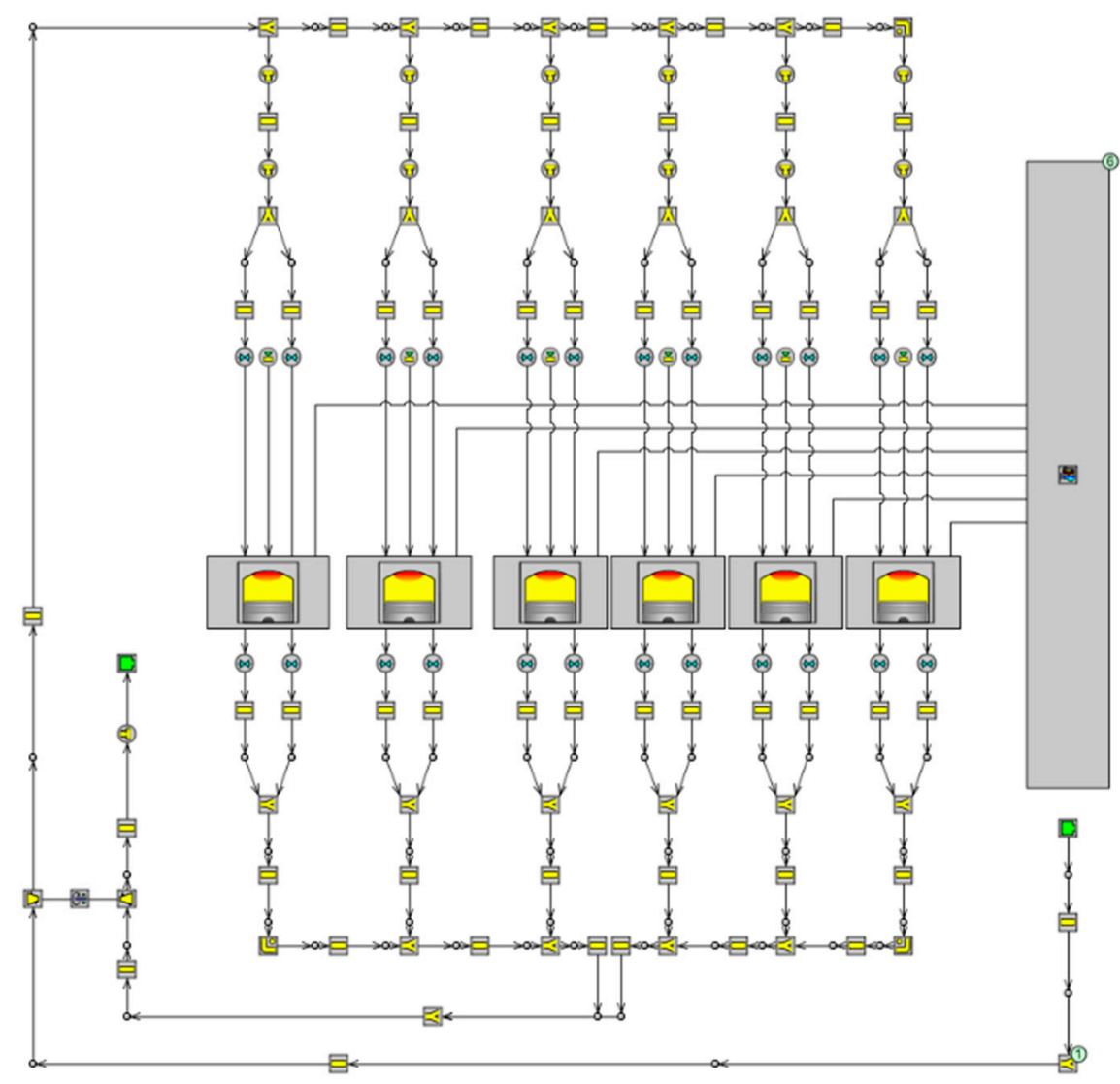

Figure 1. Simulation model of diesel engine.

Simulation model of the diesel engine is employed to figure out such performance indexes of diesel engine as its power, torque, in-cylinder heat dissipation, in-cylinder maximum pressure, highest exhaust temperature, and specific fuel consumption.

\subsection{Test Equipment}

This paper made use of the plateau-simulated diesel engine bench test lab to finish verification of the simulation model. Figure 2 is a schematic diagram of the bench test. The test system is mainly made up of control system, diesel engine and start moto, dynamo meter, combustion analysis system, and control unit. The control system can control the whole diesel engine bench test lab, measure and process the data. Diesel engine and start moto is the object of study and the core part of the bench. Dynamo meter can be used to measure the torque and power of the engine and calculate the in-cylinder heat dissipation. Combustion analysis system can adjust the inlet value, exhaust value and the oil atomizer of the engine to control the working state parameters. In the analysis system, $\mathrm{P}_{1}, \mathrm{P}_{2}, \mathrm{P}_{3}$ are the control unit to adjust the oil atomizer, exhaust value and inlet value. $P_{2}$ can measure the highest exhaust temperature. The value of in-cylinder maximum pressure is measured by this analysis system too. The function of control unit is to create the plateau environment in the lab. The control unit is 
mainly made up of filter, cooling part, compressor, temperature control part, humidity control part and outlet cooling part. Figure 3 is the detail schematic diagram of the control unit. The test lab can simulate conditions at altitude ranging from 0-4500 $\mathrm{m}$ (with corresponding atmospheric pressure ranging from $101.3 \mathrm{kPa}$ to $57.57 \mathrm{kPa}$ ) and apply accurate control and continuous regulation to inlet pressure, temperature, and humidity. The measuring and controlling accuracy of each device is listed in Table 2.

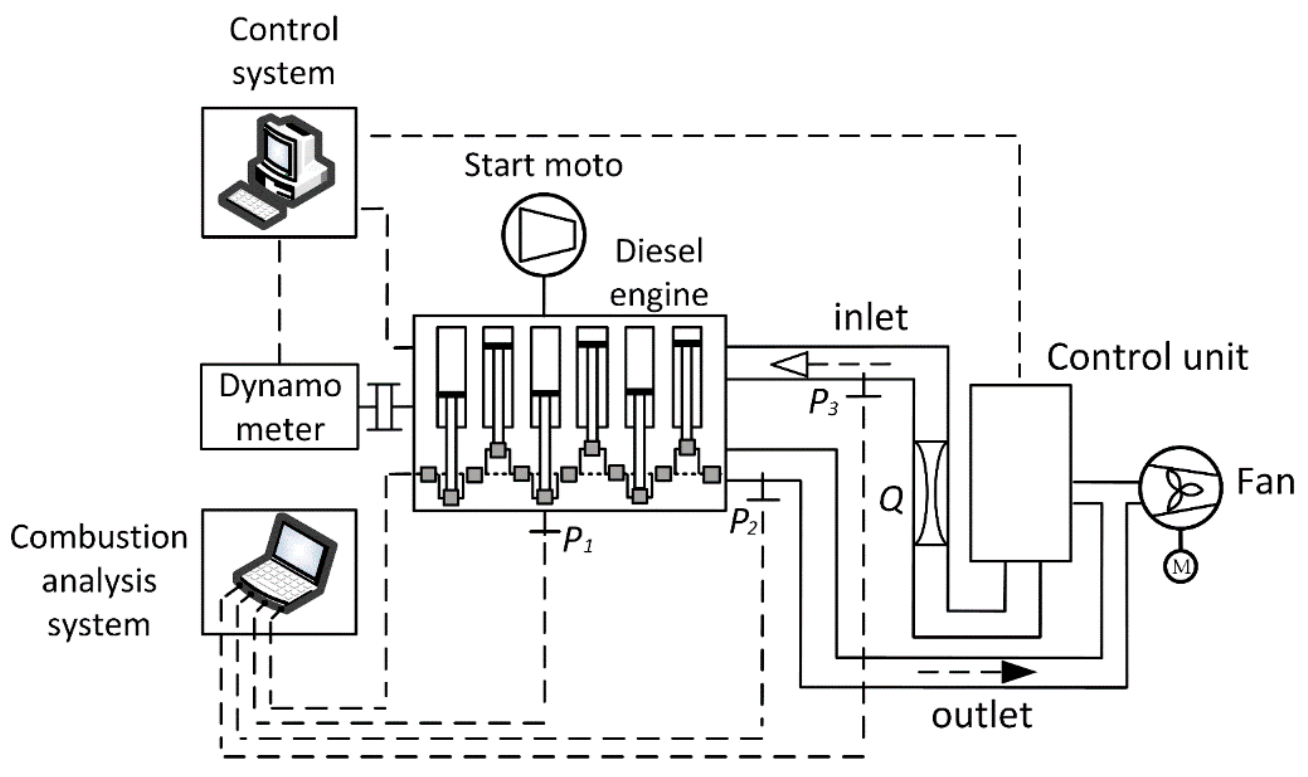

Figure 2. Schematic diagram of bench test.

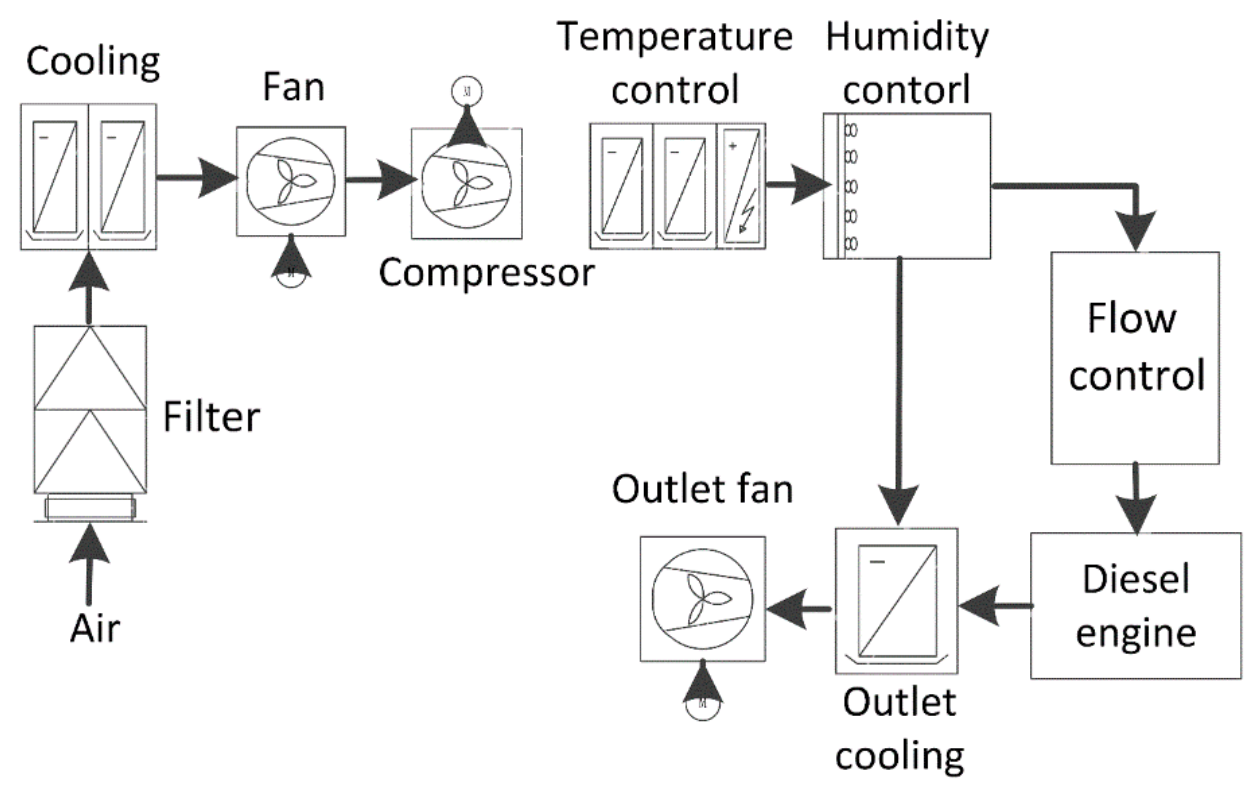

Figure 3. Schematic diagram of control unit.

Table 2. The accuracy and specification of each device.

\begin{tabular}{ccc}
\hline Device & Specification & Accuracy \\
\hline Dynamo meter & QZTI-QZ1030 & $\begin{array}{c}\text { Minus 0.1 Kw } \\
\text { Minus 0.01 Nm }\end{array}$ \\
\hline Combustion analysis system & LUBO-BO3010 & $\begin{array}{c}\text { Minus 0.1 K } \\
\text { Minus 0.1 Pa }\end{array}$ \\
\hline
\end{tabular}


Table 2. Cont.

\begin{tabular}{ccc}
\hline Device & Specification & Accuracy \\
\hline $\mathrm{P}_{1}$ & BOSCH-HDEV-1 0445 110317 & Minus 1 mg \\
$\mathrm{P}_{2}$ & Aepes 15035 & Minus 0.1 K \\
$\mathrm{P}_{3}$ & Aepes 15035 & Minus 0.1 K \\
Cooling unit & ZHIXING-YWZX-18 & Minus 1 K \\
Temperature unit & REYOU-RY01 & Minus 0.1 K \\
Humidity unit & KZP-5-CA & Minus 0.1\% \\
\hline
\end{tabular}

\subsection{Model Verification}

To verify the accuracy of the simulation model, we compare the data from the bench test lab and the simulation model. In Table 3, experimental values and calculated ones are compared and the errors are listed. According to the table, all the errors are minus $6 \%$, proving the model's accuracy and its applicability to subsequent calculation and analysis.

Table 3. The comparison of calculated values with experimental ones.

\begin{tabular}{|c|c|c|c|c|c|c|c|c|c|c|}
\hline \multirow[t]{2}{*}{ Altitude/m } & \multirow[t]{2}{*}{ Speed/rpm } & \multicolumn{3}{|c|}{ Power/kW } & \multicolumn{3}{|c|}{ Torque/ $\mathbf{N} * \mathbf{m}$} & \multicolumn{3}{|c|}{$\begin{array}{c}\text { Specific Fuel } \\
\text { Consumption } / \mathrm{g} /(\mathbf{k W} * \mathrm{~h})\end{array}$} \\
\hline & & Experiment & Calculation & Error/\% & Experiment & Calculation & Error/\% & Experiment & Calculation & Error/\% \\
\hline \multirow{3}{*}{0} & 1600 & 525 & 518.6 & -1.24 & 3205 & 3095.1 & 3.44 & 217 & 214.2 & 3.22 \\
\hline & 1800 & 570 & 558.5 & -2.15 & 3152 & 2969.8 & 5.81 & 221 & 219.6 & 3.87 \\
\hline & 2000 & 588 & 594.7 & 1.11 & 2816 & 2839.4 & -0.82 & 232 & 230.9 & 0.45 \\
\hline \multirow{2}{*}{3700} & 1800 & 435 & 445.2 & 2.34 & 2317 & 2361.8 & 1.93 & 252 & 248.9 & 1.15 \\
\hline & 2000 & 488 & 473.9 & 2.89 & 2335 & 2262.6 & 3.13 & 261 & 272.3 & 4.27 \\
\hline
\end{tabular}

\section{Orthogonal Experiment}

\subsection{Orthogonal Experiment Design}

Orthogonal experiment is used hereby for calculation purpose to unveil the influence rules about how different working state parameters affect diesel engine's performance indexes. By referring to related literature [30], five parameters are finally selected as working state optimization parameters of diesel engine, including inlet valve opening angle $\alpha_{i n}$, exhaust valve opening angle $\alpha_{\text {out }}$, supply quantity of diesel $\beta_{o i l}$, advance angle of injection $\alpha_{o i l}$, and compressor flow coefficient $\beta_{\text {comp }}$. Each factor sets five levels to calculate and analyze, and thus $\mathrm{L}_{25}\left(5^{6}\right)$ orthogonal experimental form is chosen for experimental design. In the form, there are all together six factors that contain five levels each, and it amounts to 25 sub-experiments. Values corresponding to five levels of each factor are listed in Table 4 . In the table, the value of each level corresponding the relative change from the original value. For example, the level 1 of $\alpha_{\text {in }}$ is -0.1 , which means that inlet valve opening angle of level 1 is $0.1^{\circ} \mathrm{C}$ former than the original one. The level 2 of $\beta_{\text {oil }} 185$, which means in this level, the supply quantity of diesel is $185 \mathrm{mg}$ every cycle in a single cylinder (the original value is $186 \mathrm{mg}$ ). Each level is one operating regime of the engine. During calculation, ambient conditions are set as $3700 \mathrm{~m}$ altitude and engine's speed is $2000 \mathrm{rpm}$. Evaluation indexes output by the orthogonal experiment include power $P$, torque $N$, in-cylinder heat dissipation $Q$, in-cylinder maximum pressure $P_{m i c}$, and highest exhaust temperature $T_{m o}$. 
Table 4. Values of five levels corresponding to five factors.

\begin{tabular}{cccccc}
\hline Parameters & Level1 & Level2 & Level3 & Level4 & Level5 \\
\hline$\alpha_{\text {in }}$ & -0.1 & -0.05 & 0.00 & 0.05 & 0.1 \\
$\alpha_{\text {out }}$ & -0.1 & -0.05 & 0.00 & 0.05 & 0.1 \\
$\beta_{\text {oil }}$ & 184 & 185 & 186 & 187 & 188 \\
$\alpha_{\text {oil }}$ & -19.8 & -19.9 & -20.0 & -20.1 & -20.2 \\
$\beta_{\text {comp }}$ & 0.98 & 0.99 & 1.00 & 1.01 & 1.02 \\
\hline
\end{tabular}

\subsection{Analysis of Results}

Calculation is performed in above-mentioned 25 groups of experiments with established diesel engine working simulation model. The values of working state parameters and results of corresponding performance indexes are illustrated in Table 5.

Table 5. Values and results of the orthogonal experiment.

\begin{tabular}{|c|c|c|c|c|c|c|c|c|c|c|}
\hline Number & $\alpha_{i n}$ & $\alpha_{\text {out }}$ & $\beta_{o i l}$ & $\alpha_{o i l}$ & $\beta_{\text {comp }}$ & $\begin{array}{c}P \\
\mathrm{~kW}\end{array}$ & $\begin{array}{c}N \\
\mathrm{Nm}\end{array}$ & $\underset{\mathbf{k W}}{Q}$ & $\begin{array}{c}P_{\text {mic }} \\
\text { bar }\end{array}$ & $\begin{array}{c}T_{m o} \\
\mathrm{~K}\end{array}$ \\
\hline 1 & -0.10 & -0.10 & 184 & -19.8 & 0.98 & 539.102 & 2573.942 & 442.446 & 84.020 & 628.571 \\
\hline 2 & -0.10 & -0.05 & 185 & -19.9 & 0.99 & 507.822 & 2424.594 & 477.706 & 74.135 & 677.565 \\
\hline 3 & -0.10 & 0.00 & 186 & -20.0 & 1.00 & 505.106 & 2411.628 & 475.270 & 86.090 & 641.877 \\
\hline 4 & -0.10 & 0.05 & 187 & -20.1 & 1.01 & 515.756 & 2462.477 & 454.106 & 74.063 & 649.079 \\
\hline 5 & -0.10 & 0.10 & 188 & -20.2 & 1.02 & 518.199 & 2474.143 & 461.823 & 79.071 & 596.965 \\
\hline 6 & -0.05 & -0.10 & 185 & -20.0 & 1.01 & 417.989 & 1995.689 & 470.706 & 78.304 & 588.217 \\
\hline 7 & -0.05 & -0.05 & 186 & -20.1 & 1.02 & 435.060 & 2077.195 & 446.102 & 76.954 & 768.566 \\
\hline 8 & -0.05 & 0.00 & 187 & -20.2 & 0.98 & 411.628 & 1965.316 & 448.109 & 73.542 & 591.593 \\
\hline 9 & -0.05 & 0.05 & 188 & -19.8 & 0.99 & 499.071 & 2382.812 & 473.144 & 73.105 & 614.965 \\
\hline 10 & -0.05 & 0.10 & 184 & -19.9 & 1.00 & 444.772 & 2123.565 & 466.648 & 92.540 & 656.302 \\
\hline 11 & 0.00 & -0.10 & 186 & -20.2 & 0.99 & 433.272 & 2068.658 & 462.699 & 79.037 & 655.711 \\
\hline 12 & 0.00 & -0.05 & 187 & -19.8 & 1.00 & 507.444 & 2422.792 & 440.439 & 82.539 & 659.692 \\
\hline 13 & 0.00 & 0.00 & 188 & -19.9 & 1.01 & 438.336 & 2092.835 & 447.014 & 83.898 & 618.242 \\
\hline 14 & 0.00 & 0.05 & 184 & -20.0 & 1.02 & 431.890 & 2062.058 & 446.278 & 88.036 & 652.239 \\
\hline 15 & 0.00 & 0.10 & 185 & -20.1 & 0.98 & 433.986 & 2072.067 & 454.402 & 86.292 & 697.843 \\
\hline 16 & 0.05 & -0.10 & 187 & -19.9 & 1.02 & 433.639 & 2070.409 & 454.314 & 73.458 & 623.716 \\
\hline 17 & 0.05 & -0.05 & 188 & -20.0 & 0.98 & 436.549 & 2084.302 & 444.473 & 82.248 & 676.876 \\
\hline 18 & 0.05 & 0.00 & 184 & -20.1 & 0.99 & 443.854 & 2119.18 & 465.871 & 95.166 & 670.871 \\
\hline 19 & 0.05 & 0.05 & 185 & -20.2 & 1.00 & 409.677 & 1956.001 & 474.346 & 72.792 & 643.354 \\
\hline 20 & 0.05 & 0.10 & 186 & -19.8 & 1.01 & 522.206 & 2493.273 & 454.277 & 84.033 & 626.009 \\
\hline 21 & 0.10 & -0.10 & 188 & -20.1 & 1.00 & 425.114 & 2029.706 & 457.115 & 81.119 & 671.388 \\
\hline 22 & 0.10 & -0.05 & 184 & -20.2 & 1.01 & 410.100 & 1958.022 & 446.018 & 88.958 & 720.008 \\
\hline 23 & 0.10 & 0.00 & 185 & -19.8 & 1.02 & 516.548 & 2466.257 & 472.338 & 81.741 & 616.278 \\
\hline 24 & 0.10 & 0.05 & 186 & -19.9 & 0.98 & 447.409 & 2136.156 & 471.257 & 76.117 & 610.700 \\
\hline 25 & 0.10 & 0.10 & 187 & -20.0 & 0.99 & 417.703 & 1994.322 & 450.209 & 81.416 & 646.779 \\
\hline
\end{tabular}

Calculation results of performance indexes in Table 5 are summarized and put into analysis as shown in Table 6. In the table, I-V represent the sum of corresponding values of level 1 to 5 of each factor, and $\mathrm{R}$ denotes the difference between maximum and minimum value of $\mathrm{I}-\mathrm{V}$ in different levels. Since power and torque of diesel engine exists the following equation [31], torque is not analyzed in the table.

$$
P=\frac{N n}{9549},
$$

where $P$ denotes the power, $N$ denotes the torque, and $n$ denotes the speed of the engine. 
Table 6. Statistical analysis of calculation results.

\begin{tabular}{ccccccc}
\hline Indexes & Level & $\boldsymbol{\alpha}_{\text {in }}$ & $\boldsymbol{\alpha}_{\text {out }}$ & $\boldsymbol{\beta}_{\text {oil }}$ & $\boldsymbol{\alpha}_{\text {oil }}$ & $\boldsymbol{\beta}_{\text {comp }}$ \\
\hline \multirow{6}{*}{$P / \mathrm{kW}$} & I & 2585.985 & 2249.115 & 2269.720 & 2584.370 & 2268.675 \\
& II & 2208.520 & 2296.975 & 2286.020 & 2271.980 & 2301.720 \\
& III & 2244.930 & 2315.470 & 2343.055 & 2209.235 & 2292.115 \\
& IV & 2245.925 & 2303.800 & 2286.170 & 2253.770 & 2304.385 \\
& V & 2216.875 & 2336.865 & 2317.270 & 2182.875 & 2335.335 \\
& R & 377.465 & 87.7500 & 73.335 & 401.495 & 66.660 \\
\hline \multirow{5}{*}{$/ \mathrm{kW}$} & I & 2301.350 & 2257.280 & 2267.260 & 2252.645 & 2253.685 \\
& II & 2274.705 & 2244.740 & 2272.495 & 2306.940 & 2319.630 \\
& III & 2243.830 & 2278.600 & 2309.605 & 2256.935 & 2313.815 \\
& IV & 2293.280 & 2319.130 & 2247.175 & 2270.595 & 2242.120 \\
& V & 2266.935 & 2280.360 & 2283.570 & 2292.995 & 2250.855 \\
& R & 57.520 & 74.390 & 62.430 & 54.295 & 77.510 \\
\hline \multirow{5}{*}{$P_{\text {mic }} /$ bar } & I & 237.380 & 395.940 & 448.720 & 405.440 & 402.215 \\
& II & 394.445 & 404.835 & 393.265 & 400.150 & 402.860 \\
& III & 419.800 & 420.435 & 402.230 & 416.090 & 415.080 \\
& IV & 407.695 & 384.110 & 385.020 & 413.595 & 409.255 \\
& V & 409.350 & 423.350 & 399.440 & 393.400 & 399.260 \\
& R & 25.355 & 39.240 & 63.700 & 22.690 & 15.820 \\
\hline$T_{\text {mo }} / \mathrm{K}$ & I & 3194.060 & 3167.600 & 3327.995 & 3175.515 & 3205.580 \\
& II & 3219.645 & 3502.705 & 3223.255 & 3186.525 & 3265.895 \\
& IV & 3283.725 & 3138.865 & 3332.865 & 3205.990 & 3272.615 \\
& V & 3265.830 & 3170.335 & 3170.860 & 3457.750 & 3231.555 \\
& R & 89.665 & 363.840 & 162.005 & 282.235 & 67.035 \\
\hline
\end{tabular}

As illustrated in Table 6, four working state indexes, i.e., diesel engine power $P$, in-cylinder heat dissipation $Q$, in-cylinder maximum pressure $P_{m i c}$, and highest exhaust temperature $T_{m o}$ are most affected by advance angle of injection $\alpha_{\text {oil }}$, compressor flow coefficient $\beta_{\text {comp }}$, supply quantity of diesel $\beta_{\text {oil }}$ and exhaust valve opening angle $\alpha_{\text {out }}$ seperately. Table 7 presents significance test and variance analysis results of how five factors affecting four indexes. In the table, SS denotes sum of square, $\mathrm{F}$ denotes $\mathrm{F}$ value, Sig denotes significance, if there is a * sign there, it means that the parameter has the significance influence on the state index. According to the table, inlet valve opening angle $\alpha_{i n}$ and advance angle of injection $\alpha_{\text {oil }}$ has prominent effects on diesel engine power, effect of supply quantity of diesel $\beta_{\text {oil }}$ is more prominent on in-cylinder heat dissipation $Q$ and in-cylinder maximum pressure $P_{m i c}$, and exhaust valve opening angle $\alpha_{\text {out }}$ has a greater influence on highest exhaust temperature $T_{m o}$.

Table 7. Significance test and variance analysis of calculation results.

\begin{tabular}{ccccccccccccc}
\hline \multirow{2}{*}{ Parameters } & \multicolumn{3}{c}{$\mathbf{P} / \mathbf{k W}$} & \multicolumn{4}{c}{$\mathbf{Q} / \mathbf{k W}$} & \multicolumn{3}{c}{$\boldsymbol{P}_{\text {mic }} / \mathbf{b a r}$} & \multicolumn{3}{c}{$\boldsymbol{T}_{\boldsymbol{m o}} / \mathbf{K}$} \\
\cline { 2 - 13 } & SS & F & Sig & SS & F & Sig & SS & F & Sig & SS & F & Sig \\
\hline$\alpha_{\text {in }}$ & $20,604.380$ & 2.355 & $*$ & 162.232 & 0.253 & & 82.420 & 0.458 & & 1159.354 & 0.161 & \\
$\alpha_{\text {out }}$ & 842.061 & 0.096 & & 535.729 & 0.836 & & 218.156 & 1.211 & & $17,861.380$ & 2.486 & $*$ \\
$\beta_{\text {oil }}$ & 690.909 & 0.079 & & 1880.226 & 2.934 & $*$ & 496.850 & 2.759 & $*$ & 4998.952 & 0.696 & \\
$\alpha_{\text {oil }}$ & $21,148.790$ & 2.417 & $*$ & 145.835 & 0.228 & & 70.496 & 0.391 & & $11,282.880$ & 1.571 \\
$\beta_{\text {comp }}$ & 463.675 & 0.053 & & 479.930 & 0.749 & & 32.460 & 0.180 & & 616.487 & 0.086 \\
\hline
\end{tabular}

Taken together, the analysis above, for four indexes (i.e., power $P$, in-cylinder heat dissipation $Q$, in-cylinder maximum pressure $P_{m i c}$ and highest exhaust temperature $T_{m o}$ ), inlet valve opening angle $\alpha_{i n}$, exhaust valve opening angle $\alpha_{\text {out }}$, supply quantity of diesel $\beta_{o i l}$ and advance angle of injection $\alpha_{\text {oil }}$ produce a significant effect on them. By contrast, compressor flow coefficient $\beta_{\text {comp }}$ can affect in-cylinder heat dissipation $Q$ only, but such an effect does not vary much from exhaust valve opening 
angle $\alpha_{\text {out }}$. Moreover, variance analysis suggests this index to be insignificant for in-cylinder heat dissipation $Q$ Therefore, in subsequent analysis, this article will ignore the effect of compressor flow coefficient $\beta_{\text {comp }}$, only inlet valve opening angle $\alpha_{i n}$, exhaust valve opening angle $\alpha_{o u t}$, supply quantity of diesel $\beta_{\text {oil }}$ and advance angle of injection $\alpha_{\text {oil }}$ are considered. Based on results provided in Tables 5 and 6, compressor flow coefficient $\beta_{\text {comp }}$ is set to be 1.01 in following calculation. The results calculated from orthogonal experiment are discrete points, which cannot be directly applied to the following optimization. So, a kind of RBF-NN-based performance indexes prediction method is suggested on the basis of orthogonal experiment calculation results.

\section{RBFNN-Based Performance Prediction Method}

Radial basis function neural network (RBF-NN) is proposed to deal with the problem that four working state parameters and corresponding five performance indexes of the diesel engine are discrete points.

\subsection{Fundamental Model}

RBF-NN usually contains three single hidden layers, namely input layer composed of data or signal source, hidden layer of neuron kernel function, and output layer of linear weighting of neuron.

Corresponding mathematical model [5] is as follows:

$$
y_{i}=\sum_{i=1}^{n_{c}} w_{i} g\left(\left\|x-c_{i}\right\| / \sigma_{i}\right)+b
$$

where $x$ indicates input vector (the value of $x$ are 4 to-be-optimized parameters of diesel engine: inlet valve opening angle $\alpha_{i n}$, exhaust valve opening angle $\alpha_{\text {out }}$, supply quantity of diesel $\beta_{\text {oil }}$ and advance angle of injection $\left.\alpha_{o i l}\right), w_{i}$ indicates output layer weight, $g\left(\left\|x-c_{i}\right\| / \sigma_{i}\right)$ indicates radial basis function, $c_{i}$ indicates center of radial basis function, $\sigma_{i}$ indicates width, $b$ indicates output layer threshold value, $n_{c}$ indicates number of neurons in hidden layer, $\left\|x-c_{i}\right\|$ indicates vector norm of distance from $x$ to $c_{i}$.

Gaussian function is selected as radial basis function, so neuron $i$ can be output as:

$$
R_{i}(x)=\exp \left(-\left\|x-c_{i}\right\|^{2} /\left(2 \sigma_{i}^{2}\right)\right),
$$

Corresponding mapping relation is:

$$
\mathrm{y}=f(x)=W R=\sum_{i=1}^{n_{c}} w_{i} R_{i}(x),
$$

where $W$ means weight of output layer, $R$ means output value of neuron in hidden layer. What the model outputs are five performance indexes of diesel engine, namely power $P$, torque $N$, in-cylinder heat dissipation $Q$, in-cylinder maximum pressure $P_{m i c}$, and highest exhaust temperature $T_{m o}$. In this article, the number of neurons in input layer is four, which corresponds to the four working state parameters. The number of neurons in output layer is five, which corresponds to the five performance indexes. The number of neurons in hidden layer is eight. The activation function in hidden layer is gaussian function. The activation function in output layer is $\tanh ()$ function.

$$
\tanh (x)=\frac{e^{x}-e^{-x}}{e^{x}+e^{-x}}
$$

This article employed the orthogonal least square method to calculate the central parameters of neurons. Figure 4 is the schematic diagram of RBF-NN. 


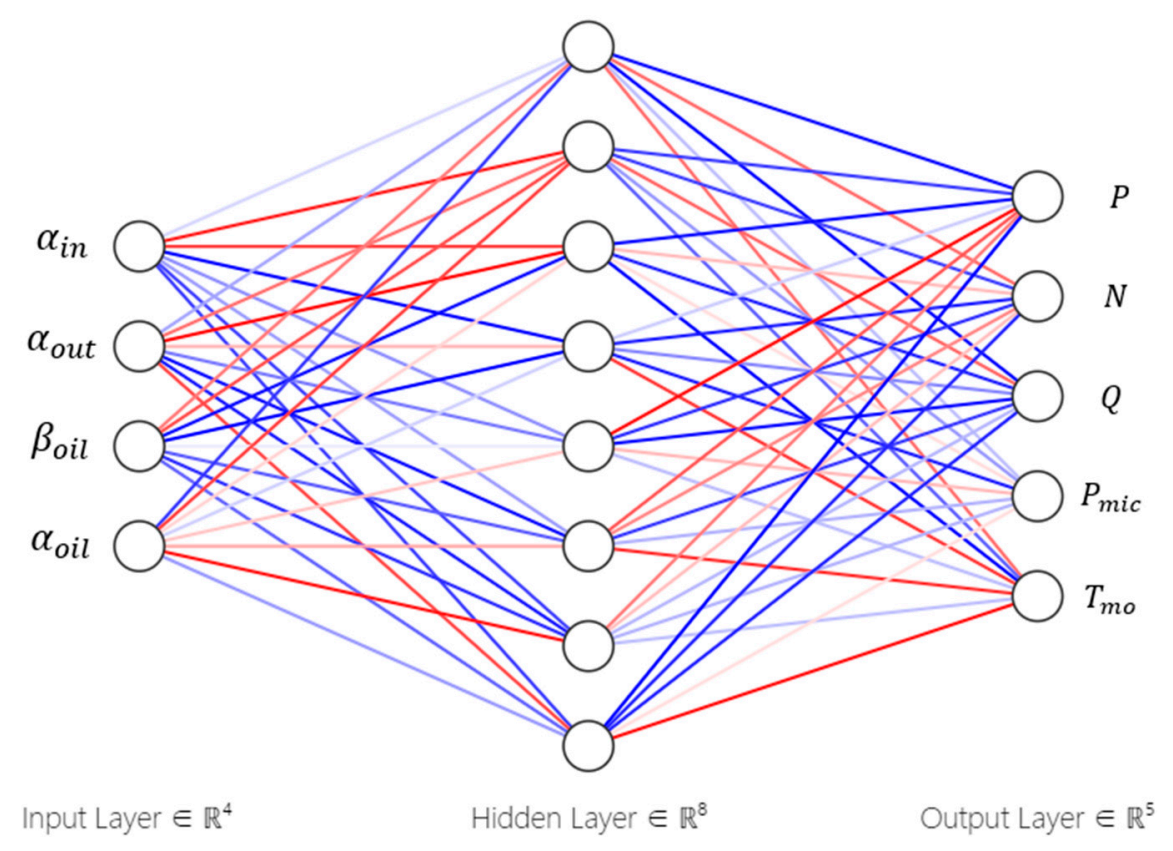

Figure 4. The schematic diagram of RBF-NN.

\subsection{Training Samples}

The established working simulation model is used in calculating all performance indexes of diesel engine working at $3700 \mathrm{~m}$ altitude and $2000 \mathrm{rpm}$. For four to-be-optimized parameters as input, progressive step is determined as one tenth of orthogonal experiment and five performance indexes are the corresponding output. Define every nine data as a sample, which include four to-be-optimized parameters and five corresponding performance indexes. Altogether, 241 samples of data are drawn from calculation, from which 221 are randomly selected as training samples, while the rest 20 as verification samples. The whole data are listed in the Table A1 in Appendix A.

The normalization of the data before analysis is applied using the following equation:

$$
x_{l}=\frac{\left|x-x_{\min }\right|}{x_{\max }-x_{\min }},
$$

where $x_{l}$ denotes normalized value, $x$ denotes original value, $x_{\max }$ denotes the maximum value under same factor, and $x_{\min }$ denotes the minimum value under same factor.

\subsection{Training Results and Verification}

RBF-NN is trained with 221 sets of normalized data and then verified with the rest 20 sets. The number of epochs is set as 200. The fitness value of the algorithm is 0.001 . Part of results are demonstrated in Table 8. A comparison of original values with predicted ones is made in Figure 5. As revealed in Table 8 and Figure 5, RBF-NN can control errors concerning all performance indexes of diesel engine minus $4.6 \%$, which testifies its accuracy and applicability to subsequent calculation and analysis. The MRE (Mean Relative Error), MSE (Mean Square Error) and RMSE (Root Mean Square Error) of the data listed in Table 9 also verify the accuracy of the prediction. Besides, this article conducted an experiment to test the accuracy of the RBFNN method, and the results are shown in the 6th paper section.

With RBF-NN, it is possible to extend the working state parameters limited to a few points to a continuous operation condition so that further calculation and analysis with GA and multi-objective optimization can proceed. Considering such reasons as computer configuration and the efficiency of training, progressive step of the training samples in this paper accounts for one tenth of data interval in orthogonal experiment and it can be adjusted flexibly when it necessary. 
Table 8. The comparison of some original values with predicted ones in RBF-NN.

\begin{tabular}{|c|c|c|c|c|c|c|c|c|}
\hline \multicolumn{2}{|c|}{ Number } & 1 & 2 & 3 & 4 & 5 & 6 & 7 \\
\hline \multicolumn{2}{|c|}{$\alpha_{i n}$} & -0.10 & -0.10 & -0.10 & -0.07 & -0.05 & -0.05 & -0.05 \\
\hline \multicolumn{2}{|c|}{$\alpha_{\text {out }}$} & -0.05 & 0.00 & 0.07 & -0.04 & -0.06 & 0.01 & 0.07 \\
\hline \multicolumn{2}{|c|}{$\beta_{\text {oil }}$} & 185.1 & 186.0 & 187.4 & 185.9 & 185.9 & 187.1 & 186.8 \\
\hline \multicolumn{2}{|c|}{$\alpha_{o i l}$} & -19.91 & -20.00 & -20.14 & -20.06 & -20.09 & -20.16 & -19.83 \\
\hline \multirow{3}{*}{$P / \mathrm{kW}$} & Original & 501.593 & 505.106 & 514.918 & 455.007 & 437.493 & 414.409 & 492.336 \\
\hline & Prediction & 483.101 & 482.585 & 522.203 & 470.095 & 434.941 & 432.271 & 490.022 \\
\hline & Error & $3.69 \%$ & $4.46 \%$ & $-1.41 \%$ & $-3.32 \%$ & $0.58 \%$ & $-4.31 \%$ & $0.47 \%$ \\
\hline \multirow{3}{*}{ N/Nm } & Original & 2394.856 & 2411.628 & 2458.475 & 2172.431 & 2088.808 & 1978.597 & 2350.660 \\
\hline & Prediction & 2357.363 & 2444.548 & 2441.914 & 2123.126 & 2010.279 & 2055.681 & 2341.463 \\
\hline & Error & $1.57 \%$ & $-1.37 \%$ & $0.67 \%$ & $2.27 \%$ & $3.76 \%$ & $-3.90 \%$ & $0.39 \%$ \\
\hline \multirow{3}{*}{$Q / \mathrm{kW}$} & Original & 471.859 & 475.270 & 455.586 & 475.307 & 452.847 & 444.221 & 480.521 \\
\hline & Prediction & 462.525 & 486.206 & 474.749 & 496.970 & 448.007 & 425.008 & 482.631 \\
\hline & Error & $1.98 \%$ & $-2.30 \%$ & $-4.21 \%$ & $-4.56 \%$ & $1.07 \%$ & $4.32 \%$ & $-0.44 \%$ \\
\hline \multirow{3}{*}{$P_{\text {mic }} /$ bar } & Original & 74.446 & 86.090 & 75.799 & 79.753 & 77.826 & 72.455 & 80.498 \\
\hline & Prediction & 72.683 & 85.040 & 75.829 & 78.956 & 77.088 & 74.190 & 81.949 \\
\hline & Error & $2.37 \%$ & $1.22 \%$ & $-0.04 \%$ & $1.00 \%$ & $0.95 \%$ & $-2.39 \%$ & $-1.80 \%$ \\
\hline \multirow{3}{*}{$T_{m o} / \mathrm{K}$} & Original & 666.086 & 641.877 & 626.026 & 600.012 & 757.700 & 585.506 & 639.783 \\
\hline & Prediction & 645.877 & 664.541 & 633.775 & 586.622 & 764.748 & 599.070 & 643.169 \\
\hline & Error & $3.03 \%$ & $-3.53 \%$ & $-1.24 \%$ & $2.23 \%$ & $-0.93 \%$ & $-2.32 \%$ & $-0.53 \%$ \\
\hline
\end{tabular}

Table 9. The MRE, MSE, RMSE of the data.

\begin{tabular}{cccccc}
\hline Parameter & $\boldsymbol{P} / \mathbf{k W}$ & $\mathbf{N} / \mathbf{N m}$ & $\boldsymbol{Q} / \mathbf{k W}$ & $\boldsymbol{P}_{\boldsymbol{m i c}} / \mathbf{b a r}$ & $\boldsymbol{T}_{\boldsymbol{m o}} / \mathbf{K}$ \\
\hline MRE & -0.0017 & 0.0061 & 0.0067 & 0.0067 & 0.0052 \\
MSE & 0.0212 & 0.0080 & 0.0557 & 0.0103 & 0.0124 \\
RMSE & 0.1456 & 0.0895 & 0.2360 & 0.1017 & 0.1114 \\
\hline
\end{tabular}

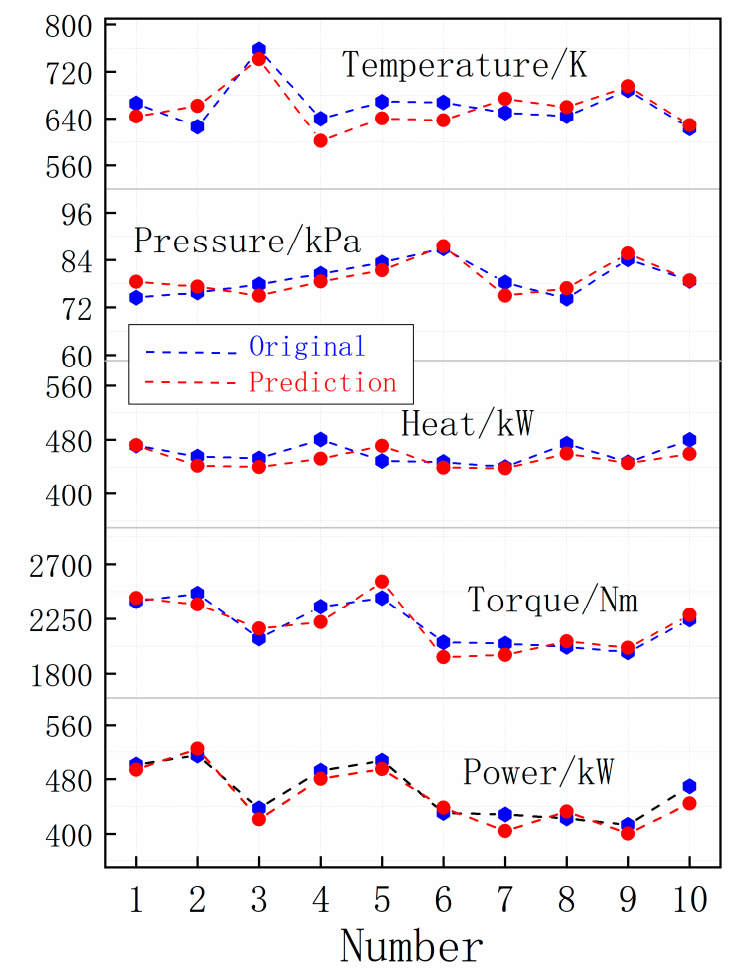

Figure 5. The comparison of original values with calculated ones in RBF-NN. 


\section{RBF-NN and GACMOO Based Multi-Objective Optimization of State Parameters}

On the basis of analysis above, genetic algorithm-based cycle multi-objective optimization method (GACMOO) is proposed. When combined with RBF-NN algorithm described above, it can simultaneously solve a string of problems such as wide scope of initial optimization parameters, non-intelligent decision-making process, and difficulty in taking into account several optimization objects at one time [32].

\subsection{Operating Process}

In this paper, RBF-NN and GA are adopted to perform a cycle multi-objective optimization on three performance indexes: diesel engine power $P$, torque $N$ and in-cylinder heat dissipation Q. This algorithm is called Radial Basis Function Neural Network \& Genetic Algorithm Cycle Multi-Objective Optimization (RBFNN \& GACMOO).

The basic procedure of using RBFNN \& GACMOO algorithm to perform multi-objective optimization on diesel engine operating process is as follows:

- (1) Make prediction about diesel engine's performance with RBF-NN:

Initial values of 4 to-be-optimized parameters $\left(\alpha_{i n}, \alpha_{o u t}, \beta_{\text {oil }}\right.$, and $\left.\alpha_{\text {oil }}\right)$ are introduced into trained RBF-NN to predict 5 performance parameters $\left(P, N, Q, P_{m i c}\right.$, and $\left.T_{m o}\right)$.

- (2) Calculate functional value of fitness:

Fitness function values of three performance indexes are figured out by combining boundary conditions formula with fitness function;

- (3) Determine optimal performance indexes of diesel engine:

GA is employed to calculate optimal values of performance functions. After getting the results of each cycle, the latest optimal values derived from calculation are compared with existing optimal values. If the former turns out to be better, it will be saved; otherwise, optimization parameters will be updated for continuous calculation and next cycle.

- (4) Update weight coefficients of fitness function:

The GA-derived optimal values of diesel engine's four to-be-optimized parameters and corresponding optimal performance indexes are used to substitute data in column five of Table 10. Then data in the table are re-arranged by a descending order and then used to calculate weight coefficients of fitness function again;

- • (5) Iterative computations:

Step 1 through 4 are repeated until weight coefficients no longer changes.

Specific operating process is as demonstrated in Figure 6. 


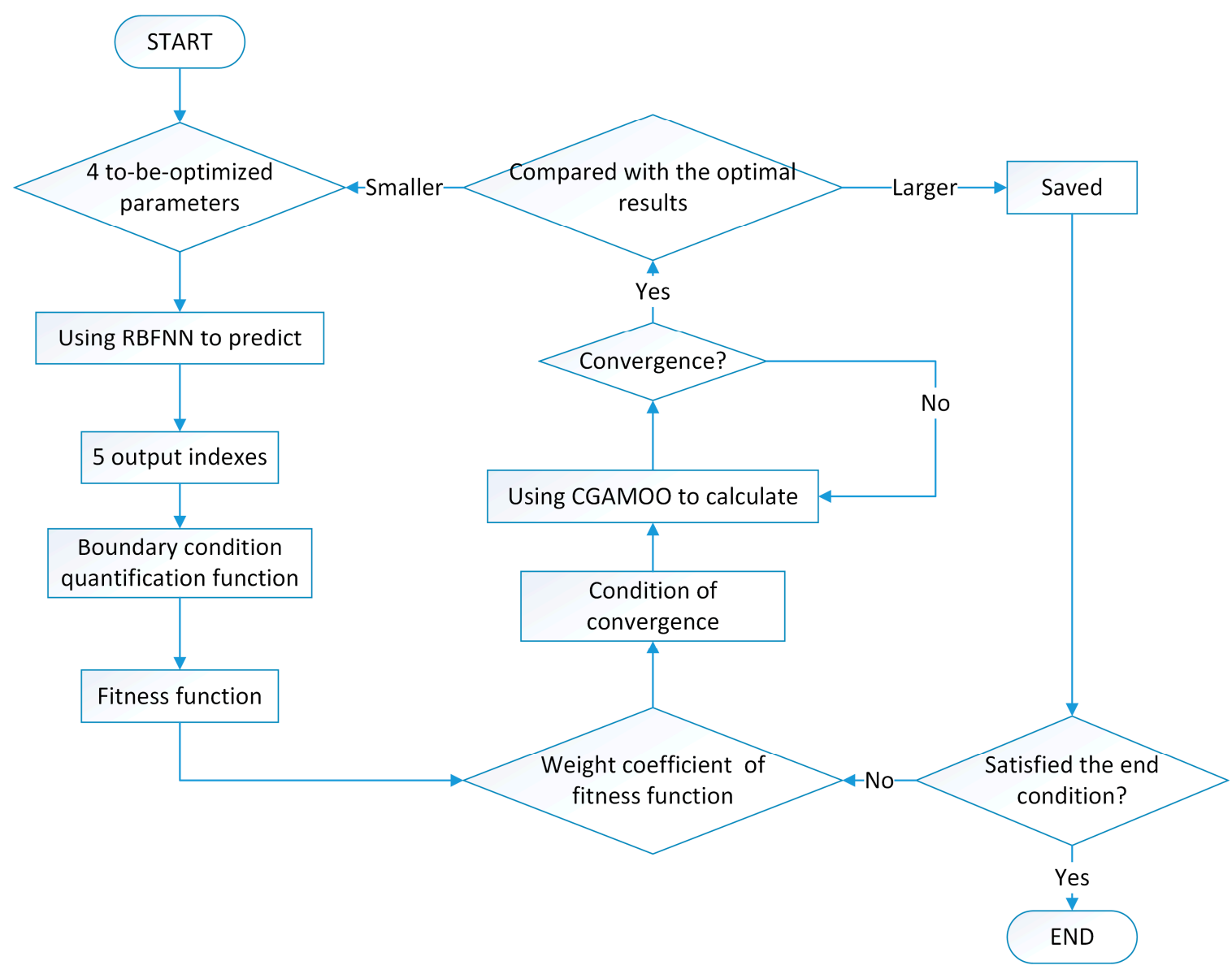

Figure 6. Operating process chart of RBFNN \& GACMOO method.

\subsection{Boundary Condition Quantification Function}

According to the practical experience and the results in Tables 3 and 5, when diesel engine works at $3700 \mathrm{~m}$ altitude and $2000 \mathrm{rpm}$, its power $P$, torque $N$, in-cylinder heat dissipation $Q$ and in-cylinder maximum pressure $P_{\text {mic }}$ cannot be lower than $470 \mathrm{~kW}, 2330 \mathrm{Nm}, 450 \mathrm{~kW}$, and 70 bar, respectively, while highest exhaust temperature $T_{m o}$ cannot exceed $700 \mathrm{~K}$. In order to embody limitations on those indicators in the algorithm, following boundary condition quantification functions are introduced for those related indicators:

$$
\begin{gathered}
Q_{1}(X)=Q_{p}(X)=P(X) / 470-1, \\
Q_{2}(X)=Q_{n}(X)=N(X) / 2330-1, \\
Q_{3}(X)=Q_{q}(X)=Q(X) / 450-1, \\
Q_{4}(X)=Q_{m i c}(X)=P_{\text {mic }}(X) / 70-1, \\
Q_{5}(X)=Q_{m o}(X)=1-T_{m o}(X) / 700 \\
(X)=\left(\alpha_{\text {in }}, \alpha_{\text {out }}, \beta_{\text {oil }}, \alpha_{\text {oil }}\right)^{T}
\end{gathered}
$$

where $Q_{p}(X), Q_{n}(X), Q_{q}(X), Q_{m i c}(X)$, and $Q_{m o}(X)$ indicate working condition quantification function of diesel engine's power, torque, in-cylinder heat dissipation, in-cylinder maximum pressure and highest exhaust temperature, respectively; while $P(X), N(X), Q(X), P_{m i c}(X)$, and $T_{m o}(X)$ represent diesel engine's power, torque, in-cylinder heat dissipation, in-cylinder maximum pressure and highest exhaust temperature when the input parameter is $X$, respectively. 


\subsection{Fitness Function}

The optimization process of the GA is called "natural selection law", which looks for and selects optimal objectives through fitness function. Fitness function, on the other hand, should be designed on the basis of specific model-influencing factors, as its quality directly decides the algorithm's calculating accuracy and efficiency [33].

The main goal of this paper is to figure out the optimal performance indexes of diesel engine in plateau environment by adjusting its working state parameters. As to diesel engine, primary performance indexes to be considered include its power, torque, in-cylinder heat dissipation, in-cylinder maximum pressure and highest exhaust temperature. Therefore, the fitness function must be related with these indexes. In fact, the in-cylinder pressure directly correlates with the power and torque, and the exhaust temperature partly correlates with the in-cylinder heat dissipation. To reduce the cost of calculation, we ignore the effect of in-cylinder maximum pressure and highest exhaust temperature when determining the fitness function.

Thus, three objective-optimizing fitness functions are introduced hereby:

$$
\begin{gathered}
P_{\text {goal }}=P(X)-\sum_{i=1}^{5} \alpha_{i} Q_{i}(X), \\
T_{\text {goal }}=N(X)-\sum_{j=1}^{5} \beta_{j} Q_{j}(X), \\
Q_{\text {goal }}=Q(X)-\sum_{l=1}^{5} \gamma_{l} Q_{l}(X),
\end{gathered}
$$

where, $P_{\text {goal }}, T_{\text {goal }}$, and $Q_{\text {goal }}$ represent objective-optimizing functions for diesel engine's power, torque and in-cylinder heat dissipation, respectively, $\alpha_{i}, \beta_{j}$, and $\gamma_{l}$ are weight coefficients corresponding to quantification functions in the objective-optimizing fitness functions.

\subsection{Initial Value of Weight Coefficients}

Through the analysis of diesel engine working process, boundary condition quantification function and fitness function for plateau state optimization are set up. In addition, the core bridge between those two functions is weight coefficients [34], which will be determined with the following procedure.

Since every fitness function contains five unknown weight coefficients, five sets of data are required for obtaining a solution. The first five relatively optimal solutions concerning power, torque and heat dissipation in Table 5 calculating from orthogonal experiments are substituted into the formula above, and fitness function value is set to be 0 , then following formulas can be derived:

$$
\begin{aligned}
& P\left(X_{i-k}\right)-\sum_{i=1}^{5} \alpha_{i} Q_{i}\left(X_{i-k}\right)=0, \\
& N\left(X_{j-k}\right)-\sum_{j=1}^{5} \beta_{j} Q_{j}\left(X_{j-k}\right)=0, \\
& Q\left(X_{l-k}\right)-\sum_{l=1}^{5} \gamma_{l} Q_{l}\left(X_{l-k}\right)=0,
\end{aligned}
$$

where value of $k$ ranges from 1 to $5, X_{i-k}, X_{j-k}$, and $X_{l-k}$ corresponds to the first five optimal values of calculated power, torque and heat dissipation. Specific values and computed indexes are listed in Table 10. 
Table 10. Values and corresponding results of $X$.

\begin{tabular}{|c|c|c|c|c|c|}
\hline $\begin{array}{c}\text { Group 1: } \\
\text { Optimal } P\left(X_{i-k}\right)\end{array}$ & $X_{i-1}$ & $X_{i-2}$ & $X_{i-3}$ & $X_{i-4}$ & $X_{i-5}$ \\
\hline$\alpha_{\text {in }}$ & -0.10 & -0.10 & 0.05 & -0.05 & 0.10 \\
\hline$\alpha_{\text {out }}$ & -0.05 & 0.00 & 0.05 & 0.05 & 0.00 \\
\hline$\beta_{o i l}$ & 185 & 186 & 185 & 188 & 185 \\
\hline$\alpha_{\text {oil }}$ & -19.9 & -20.0 & -20.2 & -19.8 & -19.8 \\
\hline$P\left(X_{i-k}\right) / \mathrm{kW}$ & 507.820 & 505.100 & 409.670 & 499.070 & 516.540 \\
\hline$N\left(X_{i-k}\right) / \mathrm{Nm}$ & 2424.590 & 2411.620 & 1956.000 & 2382.810 & 2466.250 \\
\hline$Q\left(X_{i-k}\right) / \mathrm{kW}$ & 477.700 & 475.260 & 474.340 & 473.140 & 472.330 \\
\hline$P_{\text {mic }}\left(X_{i-k}\right) /$ bar & 74.130 & 86.080 & 72.792 & 73.100 & 81.740 \\
\hline$T_{m o}\left(X_{i-k}\right) / \mathrm{K}$ & 677.560 & 641.870 & 643.350 & 614.960 & 616.270 \\
\hline $\begin{array}{c}\text { Group 2: } \\
\text { Optimal } N\left(X_{j-k}\right)\end{array}$ & $X_{j-1}$ & $X_{j-2}$ & $X_{j-3}$ & $X_{j-4}$ & $X_{j-5}$ \\
\hline$\alpha_{\text {in }}$ & -0.10 & 0.05 & -0.10 & 0.10 & -0.10 \\
\hline$\alpha_{\text {out }}$ & -0.10 & 0.10 & 0.10 & 0.00 & 0.05 \\
\hline$\beta_{\text {oil }}$ & 184 & 186 & 188 & 185 & 187 \\
\hline$\alpha_{o i l}$ & -19.8 & -19.8 & -20.2 & -19.8 & -20.1 \\
\hline$P\left(X_{j-k}\right) / \mathrm{kW}$ & 539.100 & 522.210 & 518.200 & 516.550 & 0515.760 \\
\hline$N\left(X_{j-k}\right) / \mathrm{Nm}$ & 2573.940 & 2493.270 & 2474.140 & 2466.260 & 2462.480 \\
\hline$Q\left(X_{j-k}\right) / \mathrm{kW}$ & 442.450 & 454.280 & 461.820 & 472.340 & 454.110 \\
\hline$P_{\text {mic }}\left(X_{j-k}\right) /$ bar & 84.020 & 84.030 & 79.070 & 81.740 & 74.060 \\
\hline$T_{m o}\left(X_{j-k}\right) / \mathrm{K}$ & 628.570 & 626.010 & 596.960 & 616.280 & 649.080 \\
\hline $\begin{array}{c}\text { Group 3: } \\
\text { Optimal } Q\left(X_{l-k}\right)\end{array}$ & $X_{l-1}$ & $X_{l-2}$ & $X_{l-3}$ & $X_{l-4}$ & $X_{l-5}$ \\
\hline$\alpha_{\text {in }}$ & -0.10 & -0.10 & 0.05 & -0.05 & 0.10 \\
\hline$\alpha_{\text {out }}$ & -0.05 & 0.00 & 0.05 & 0.05 & 0.00 \\
\hline$\beta_{o i l}$ & 185 & 186 & 185 & 188 & 185 \\
\hline$\alpha_{o i l}$ & -19.9 & -20.0 & -20.2 & -19.8 & -19.8 \\
\hline$P\left(X_{l-k}\right) / \mathrm{kW}$ & 507.820 & 505.110 & 409.680 & 499.070 & 516.550 \\
\hline$N\left(X_{l-k}\right) / \mathrm{Nm}$ & 2424.590 & 2411.630 & 1956.000 & 2382.810 & 2466.260 \\
\hline$Q\left(X_{l-k}\right) / \mathrm{kW}$ & 477.710 & 475.270 & 474.350 & 473.140 & 472.340 \\
\hline$P_{\text {mic }}\left(X_{l-k}\right) /$ bar & 74.140 & 86.090 & 72.790 & 73.110 & 81.740 \\
\hline$T_{m o}\left(X_{l-k}\right) / \mathrm{K}$ & 677.570 & 641.880 & 643.350 & 614.970 & 616.280 \\
\hline
\end{tabular}

Through calculation, values of 15 weight coefficients are determined and shown in Table 11.

Table 11. Calculation-derived values of weight coefficients.

\begin{tabular}{cccccc}
\hline Coefficients & Values & Coefficients & Values & Coefficients & Values \\
\hline$\alpha_{1}$ & -2846.80 & $\beta_{1}$ & -3486.42 & $\gamma_{1}$ & -3516.43 \\
$\alpha_{2}$ & -6782.73 & $\beta_{2}$ & -8214.83 & $\gamma_{2}$ & -7814.67 \\
$\alpha_{3}$ & 2438.72 & $\beta_{3}$ & 2982.07 & $\gamma_{3}$ & 2461.81 \\
$\alpha_{4}$ & 4046.54 & $\beta_{4}$ & 4243.16 & $\gamma_{4}$ & 4123.19 \\
$\alpha_{5}$ & 3229.59 & $\beta_{5}$ & 2858.96 & $\gamma_{5}$ & 3978.96 \\
\hline
\end{tabular}

\subsection{Updating of Weight Coefficients}

Weight coefficients derived from calculation above are substituted into fitness functions of three to-be-optimized objectives as initial values for determining the optimal working state parameters and performance indexes of diesel engine. Afterwards, weight coefficients are re-computed on the basis of the calculation outcome. Detailed process is listed below:

- (1) Substitute weight coefficients into fitness functions of three to-be-optimized objectives for calculation; 
- (2) Substitute $X_{i-5}, X_{j-5}$ and $X_{l-5}$ in Table 10 with newest results of diesel engine's four to-be-optimized parameters and five corresponding optimal performance indexes;

- (3) Re-arrange data in five columns of group 1, 2 and 3 in Table 10 in a descending order with as $P\left(X_{i-k}\right), N\left(X_{j-k}\right)$ and $Q\left(X_{l-k}\right)$ measuring criteria;

- (4) Set value of fitness function to be 0 , and combine it with data in updated Table 10 for calculation of weight coefficients again;

- (5) Repeat step (1) to (4) as per iterative calculation process in Figure 6 until the data satisfies the convergence condition.

\subsection{Condition of Convergence}

During calculation, following condition of convergence is established:

$$
\begin{aligned}
& C_{1}=\left(\left|{P_{\text {goal }}^{\prime(n)}}_{\text {goal }}-P_{\text {goal }}^{\prime(n-1)}\right|\right) / P_{\text {goal }}^{P^{(n)}}<0.03, \\
& C_{2}=\left(\left|N_{\text {goal }}^{(n)}-N_{\text {goal }}^{(n-1)}\right|\right) / T_{\text {goal }}^{(n)}<0.03, \\
& C_{3}=\left(\left|{Q^{\prime}}_{\text {goal }}^{(n)}-{Q^{\prime}}_{\text {goal }}^{(n-1)}\right|\right) / E_{\text {goal }}^{(n)}<0.03,
\end{aligned}
$$

where, ${P^{\prime}}_{\text {goal }}^{(n)}, P_{\text {goal }}^{(n-1)},{N^{\prime}}_{\text {goal }}^{(n)} N_{\text {goal }}^{\prime(n-1)},{Q^{\prime}}_{\text {goal }}^{(n)}$, and ${Q^{\prime}}_{\text {goal }}^{(n-1)}$ represent fitness function values of diesel engine's power, torque and heat dissipation resulting from No. $\mathrm{n}$ and No. $\mathrm{n}-1$ cycle computation.

Quadric sum of three convergence indexes is monitored during the calculation:

$$
C_{4}=C_{1}^{2}+C_{2}^{2}+C_{3}^{2},
$$

In calculation, iteration number is set to last 350 cycles. What Figure 7 presents is change rules of $C$ value as iteration goes on after weight coefficients is no longer updated.

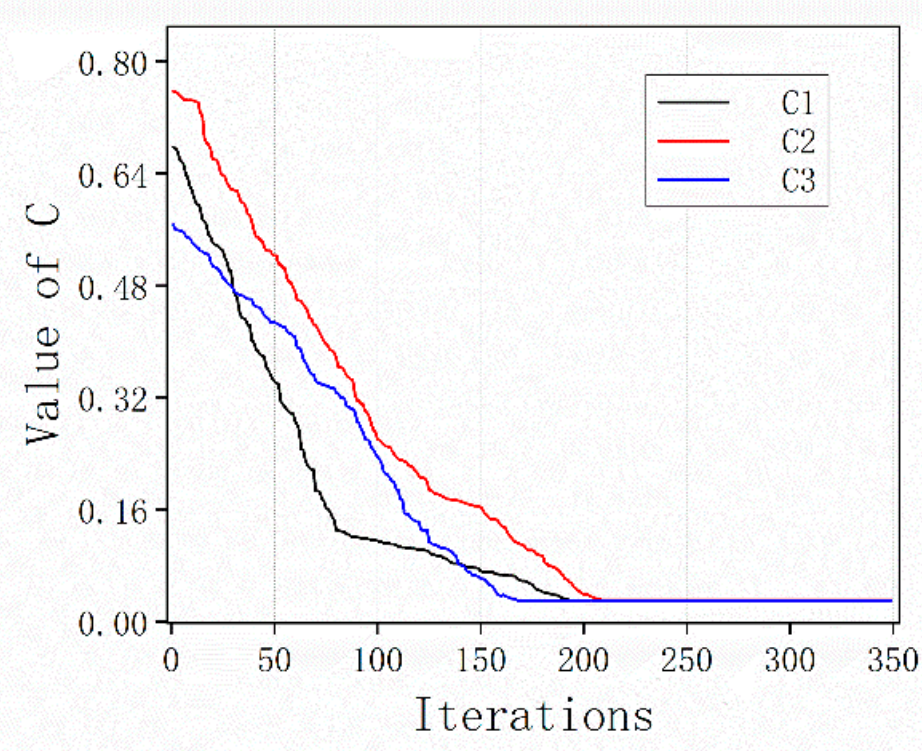

Figure 7. Change of $\mathrm{C}$ value. 


\subsection{Analysis of Calculation Results}

Values of optimal torque, power, and heat dissipation of diesel engines are figured out as shown in Table 12. As revealed by results, when working in optimal state, the engine's power, torque, and in-cylinder heat dissipation are $2520.93 \mathrm{Nm}, 528.45 \mathrm{~kW}$, and $465.32 \mathrm{~kW}$ respectively.

Table 12. Calculation results of diesel engine's optimal state parameters.

\begin{tabular}{cccccccccc}
\hline Parameters & $\boldsymbol{\alpha}_{\text {in }}$ & $\boldsymbol{\alpha}_{\text {out }}$ & $\boldsymbol{\beta}_{\text {oil }}$ & $\boldsymbol{\alpha}_{\text {oil }}$ & $\boldsymbol{P} / \mathbf{k W}$ & $\mathrm{N} / \mathrm{Nm}$ & $\boldsymbol{Q} / \mathbf{k W}$ & $\boldsymbol{P}_{\text {mic }} / \mathrm{bar}$ & $\boldsymbol{T}_{\text {mo }} / \mathrm{K}$ \\
\hline Values & -0.09 & -0.09 & 184.4 & -19.8 & 528.5 & 2520.930 & 465.320 & 80.510 & 648.180 \\
\hline
\end{tabular}

\section{Verification with Bench Test}

To verify whether the RBF-NN \& GACMOO method is both effective and accurate in diesel engine's optimization, an experiment test on diesel engine's performance in plateau environment was carried out.

Diesel engine was tested with aforesaid bench about its working state in plateau environment. Different test variables are set as shown in Table 13.

Table 13. The configuration of variables in verification experiment.

\begin{tabular}{cccccc}
\hline Number & $\boldsymbol{\alpha}_{\text {in }}$ & $\boldsymbol{\alpha}_{\text {out }}$ & $\boldsymbol{\beta}_{\text {oil }}$ & $\boldsymbol{\alpha}_{\text {oil }}$ & $\boldsymbol{\beta}_{\text {comp }}$ \\
\hline 1 & -0.09 & -0.09 & 184.4 & -19.8 & 1.01 \\
2 & -0.05 & -0.07 & 185.6 & -20.1 & 1.01 \\
3 & -0.05 & 0.07 & 186.4 & -19.8 & 1.01 \\
4 & 0.00 & -0.04 & 187.2 & -19.8 & 1.01 \\
5 & 0.05 & 0.03 & 184.5 & -20.2 & 1.01 \\
6 & 0.10 & -0.02 & 184.7 & -19.9 & 1.01 \\
\hline
\end{tabular}

In Table 13, the first group of experiment is the recommendation configurations of diesel engine parameters resulting from RBFNN \& GACMOO, whereas the second to sixth use five sets of parameters randomly selected from Table A1 for RBF-NN training and verification. Due to limited experimental conditions, it is impossible to directly measure in-cylinder heat dissipation of diesel engine by now. Therefore, only power and torque got measured. Experimental values and predicted ones of diesel engine power and torque are compared as demonstrated in Tables 14 and 15.

Table 14. Comparison of experimental values with predicted ones of diesel engine power $(\mathrm{kW})$.

\begin{tabular}{cccc}
\hline Number & Experimental Value & Predicted Value & Error \\
\hline 1 & 525.20 & 528.45 & $-0.62 \%$ \\
2 & 447.94 & 435.92 & $2.68 \%$ \\
3 & 500.71 & 475.93 & $4.95 \%$ \\
4 & 519.48 & 501.64 & $3.43 \%$ \\
5 & 405.92 & 425.56 & $-4.84 \%$ \\
6 & 503.71 & 483.10 & $4.09 \%$ \\
\hline
\end{tabular}

Table 15. Comparison of experimental values and predicted ones of diesel engine torque (Nm).

\begin{tabular}{cccc}
\hline Number & Experiment Value & Predicted Value & Error \\
\hline 1 & 2549.19 & 2520.93 & $1.11 \%$ \\
2 & 2137.06 & 2081.32 & $2.61 \%$ \\
3 & 2403.92 & 2272.32 & $5.47 \%$ \\
4 & 2490.89 & 2395.12 & $3.84 \%$ \\
5 & 1955.49 & 2031.86 & $-3.91 \%$ \\
6 & 2406.38 & 2306.60 & $4.15 \%$ \\
\hline
\end{tabular}


As shown in Tables 14 and 15, errors between experimental values and predicted ones are all minus engineering tolerance range i.e., $6 \%$, which proves accuracy of results and effectiveness of RBFNN \& GACMOO algorithm. It is worth pointing out that the error may partly from the measurement equipment of the experiment instead of totally from the trained RBF-NN.

\section{Conclusions}

The work completed in this paper mainly consists of:

(1) A simulation model is established for diesel engine working in plateau environment. Using the diesel engine bench test lab to verify the accuracy of the model.

(2) Using orthogonal experiment approach to calculate and analyze the rules that how five working state parameters (inlet valve opening angle, exhaust valve opening angle, supply quantity of diesel, advance angle of injection, and compressor flow coefficient) affecting its five performance indexes (power, torque, in-cylinder heat dissipation, in-cylinder maximum pressure, and highest exhaust temperature) of diesel engine. Results indicate inlet valve opening angle, exhaust valve opening angle, supply quantity of diesel and advance angle of injection are more prominent in affecting performance indexes, thus only those four parameters are considered in subsequent calculation and analysis.

(3) A prediction model is created to connect four working state parameters and five performance indexes of diesel engine on the basis of RBFNN method. The model is further trained with 221 samples which calculated from working simulation model, and predicting results are verified in term of its accuracy. Use of RBF-NN helps to serialize discrete working state parameters and corresponding performance indexes so as to facilitate the following calculation and optimization.

(4) Based on the above analysis, a multi-objective optimization approach called RBFNN \& GACMOO method is proposed, which is used to find the optimal working state parameters of diesel engine at $3700 \mathrm{~m}$ altitude and $2000 \mathrm{rpm}$ condition. In this method, the boundary condition quantification function, fitness function and its weight coefficients should be identified and quantified separately.

(5) Bench test verification indicates that optimal results conform to requirements of engineering accuracy. The solution can minimize in-cylinder heat dissipation and thermal load of high-temperature parts, while maintaining relatively insignificant reduction in power and torque of diesel engine working at plateau.

After establishing diesel engine simulation model and conducting an orthogonal experiment, this paper proposes a multi-objective optimization approach named RBFNN \& GACMOO specific for working state of diesel engine at plateau on the basis of Radial Basis Function Neural Network and Genetic Algorithm Cycle Multi-Objective Optimization. The proposed approach can not only guarantee a reasonable power and torque for diesel engine working at plateau environment, but also minimize in-cylinder heat accumulation and subsequent lower thermal load on high-temperature parts, thus it is able to improve the service life and reliability of the whole engine. The model and algorithm can be applied to the calculation and analysis of diesel engine's optimal working state parameters at various altitudes and rpms and offer corresponding specific control strategies. The present research will be helpful to improve working performance and reliability of heavy-duty diesel engine working at plateau.

Author Contributions: Conceptualization, J.L. and Y.D.; methodology, Y.L. and Y.D.; validation, Y.D., Y.L., X.Q. and Y.J.; data curation, Q.K.; writing—original draft preparation, T.W.; Writing-Review and editing, X.Z. and J.L.; supervision, Y.D. funding acquisition, J.L.; writing-review\& editing, S.Z. All authors have read and agreed to the published version of the manuscript.

Funding: This research received no external funding.

Conflicts of Interest: The authors declare no conflict of interest. 


\section{Appendix A}

Table A1. Whole dataset for the RBF neural network analysis.

\begin{tabular}{|c|c|c|c|c|c|c|c|c|c|}
\hline Number & $\alpha_{i n}$ & $\alpha_{\text {out }}$ & $\beta_{o i l}$ & $\alpha_{o i l}$ & $\begin{array}{c}P \\
\mathrm{~kW}\end{array}$ & $\begin{array}{c}N \\
\mathrm{Nm}\end{array}$ & $\underset{\mathbf{k W}}{Q}$ & $\begin{array}{c}P_{\text {mic }} \\
\text { bar }\end{array}$ & $\begin{array}{c}T_{m o} \\
\mathbf{K}\end{array}$ \\
\hline 1 & -0.100 & -0.100 & 184.0 & -19.80 & 539.102 & 2573.942 & 442.446 & 84.020 & 628.571 \\
\hline 2 & -0.100 & -0.095 & 184.1 & -19.81 & 536.270 & 2560.420 & 446.218 & 83.077 & 633.820 \\
\hline 3 & -0.100 & -0.090 & 184.2 & -19.82 & 540.706 & 2581.603 & 456.129 & 83.253 & 647.787 \\
\hline 4 & -0.100 & -0.085 & 184.3 & -19.83 & 531.821 & 2539.181 & 454.823 & 81.376 & 645.824 \\
\hline 5 & -0.100 & -0.080 & 184.4 & -19.84 & 526.289 & 2512.765 & 456.289 & 80.020 & 647.798 \\
\hline 6 & -0.100 & -0.075 & 184.5 & -19.85 & 530.274 & 2531.795 & 466.064 & 80.106 & 661.568 \\
\hline 7 & -0.100 & -0.070 & 184.6 & -19.86 & 529.003 & 2525.724 & 471.326 & 79.390 & 668.930 \\
\hline 8 & -0.100 & -0.065 & 184.7 & -19.87 & 525.665 & 2509.786 & 474.768 & 78.361 & 673.708 \\
\hline 9 & -0.100 & -0.060 & 184.8 & -19.88 & 512.997 & 2449.305 & 469.665 & 75.952 & 666.363 \\
\hline 10 & -0.100 & -0.055 & 184.9 & -19.89 & 501.231 & 2393.129 & 465.161 & 73.695 & 659.872 \\
\hline 11 & -0.100 & -0.050 & 185.0 & -19.90 & 507.822 & 2424.594 & 477.706 & 74.135 & 677.565 \\
\hline $12 *$ & -0.100 & -0.045 & 185.1 & -19.91 & 501.593 & 2394.856 & 471.859 & 74.446 & 666.086 \\
\hline 13 & -0.100 & -0.040 & 185.2 & -19.92 & 514.717 & 2457.516 & 484.217 & 77.648 & 680.258 \\
\hline 14 & -0.100 & -0.035 & 185.3 & -19.93 & 510.485 & 2437.309 & 480.247 & 78.255 & 671.433 \\
\hline 15 & -0.100 & -0.030 & 185.4 & -19.94 & 510.314 & 2436.493 & 480.098 & 79.474 & 667.974 \\
\hline 16 & -0.100 & -0.025 & 185.5 & -19.95 & 511.622 & 2442.738 & 481.341 & 80.928 & 666.440 \\
\hline 17 & -0.100 & -0.020 & 185.6 & -19.96 & 513.131 & 2449.944 & 482.772 & 82.422 & 665.147 \\
\hline 18 & -0.100 & -0.015 & 185.7 & -19.97 & 506.703 & 2419.256 & 476.737 & 82.631 & 653.593 \\
\hline 19 & -0.100 & -0.010 & 185.8 & -19.98 & 515.106 & 2459.375 & 484.655 & 85.264 & 661.153 \\
\hline 20 & -0.100 & -0.005 & 185.9 & -19.99 & 512.027 & 2444.675 & 481.770 & 86.011 & 653.939 \\
\hline $21 *$ & -0.100 & 0.000 & 186.0 & -20.00 & 505.106 & 2411.628 & 475.270 & 86.090 & 641.877 \\
\hline 22 & -0.090 & 0.000 & 186.2 & -19.99 & 507.442 & 2422.781 & 480.987 & 87.423 & 651.077 \\
\hline 23 & -0.080 & 0.000 & 186.4 & -19.98 & 498.529 & 2380.227 & 476.091 & 86.832 & 645.931 \\
\hline 24 & -0.070 & 0.000 & 186.6 & -19.97 & 486.357 & 2322.113 & 468.027 & 85.658 & 636.464 \\
\hline 25 & -0.060 & 0.000 & 186.8 & -19.96 & 474.142 & 2263.790 & 459.840 & 84.455 & 626.796 \\
\hline 26 & -0.050 & 0.000 & 187.0 & -19.95 & 471.203 & 2249.761 & 460.636 & 84.901 & 629.368 \\
\hline 27 & -0.040 & 0.000 & 187.2 & -19.94 & 458.771 & 2190.400 & 452.134 & 83.631 & 619.228 \\
\hline 28 & -0.030 & 0.000 & 187.4 & -19.93 & 459.529 & 2194.019 & 456.645 & 84.770 & 626.917 \\
\hline 29 & -0.020 & 0.000 & 187.6 & -19.92 & 451.304 & 2154.751 & 452.279 & 84.264 & 622.437 \\
\hline 30 & -0.010 & 0.000 & 187.8 & -19.91 & 446.959 & 2134.007 & 451.807 & 84.485 & 623.320 \\
\hline 31 & -0.100 & 0.050 & 187.0 & -20.10 & 515.756 & 2462.477 & 454.106 & 74.063 & 649.079 \\
\hline 32 & -0.100 & 0.055 & 187.1 & -20.11 & 520.874 & 2486.911 & 459.173 & 75.268 & 649.948 \\
\hline 33 & -0.100 & 0.060 & 187.2 & -20.12 & 506.445 & 2418.023 & 447.000 & 73.640 & 626.533 \\
\hline 34 & -0.100 & 0.065 & 187.3 & -20.13 & 516.084 & 2464.043 & 456.063 & 75.506 & 632.947 \\
\hline $35^{*}$ & -0.100 & 0.070 & 187.4 & -20.14 & 514.918 & 2458.475 & 455.586 & 75.799 & 626.026 \\
\hline 36 & -0.100 & 0.075 & 187.5 & -20.15 & 514.574 & 2456.832 & 455.835 & 76.211 & 620.124 \\
\hline 37 & -0.100 & 0.080 & 187.6 & -20.16 & 522.099 & 2492.761 & 463.062 & 77.794 & 623.635 \\
\hline 38 & -0.100 & 0.085 & 187.7 & -20.17 & 521.798 & 2491.327 & 463.355 & 78.218 & 617.727 \\
\hline 39 & -0.100 & 0.090 & 187.8 & -20.18 & 513.222 & 2450.378 & 456.289 & 77.393 & 602.121 \\
\hline 40 & -0.100 & 0.095 & 187.9 & -20.19 & 508.442 & 2427.556 & 452.584 & 77.127 & 591.116 \\
\hline 41 & -0.100 & 0.100 & 188.0 & -20.20 & 518.199 & 2474.143 & 461.823 & 79.071 & 596.965 \\
\hline 42 & -0.095 & 0.080 & 187.7 & -20.18 & 504.367 & 2408.099 & 459.241 & 78.402 & 591.619 \\
\hline 43 & -0.090 & 0.060 & 187.4 & -20.16 & 491.539 & 2346.854 & 457.441 & 77.869 & 587.307 \\
\hline 44 & -0.085 & 0.040 & 187.1 & -20.14 & 489.885 & 2338.958 & 466.153 & 79.123 & 596.470 \\
\hline 45 & -0.080 & 0.020 & 186.8 & -20.12 & 478.885 & 2286.438 & 466.126 & 78.891 & 594.421 \\
\hline 46 & -0.075 & 0.000 & 186.5 & -20.10 & 475.640 & 2270.944 & 473.781 & 79.956 & 602.144 \\
\hline 47 & -0.070 & -0.020 & 186.2 & -20.08 & 457.149 & 2182.657 & 466.210 & 78.452 & 590.522 \\
\hline $48^{*}$ & -0.065 & -0.040 & 185.9 & -20.06 & 455.007 & 2172.431 & 475.307 & 79.753 & 600.012 \\
\hline 49 & -0.060 & -0.060 & 185.6 & -20.04 & 433.346 & 2069.010 & 463.914 & 77.618 & 583.656 \\
\hline 50 & -0.055 & -0.080 & 185.3 & -20.02 & 421.109 & 2010.583 & 462.242 & 77.116 & 579.593 \\
\hline 51 & -0.050 & -0.100 & 185.0 & -20.00 & 417.989 & 1995.689 & 470.706 & 78.304 & 588.217 \\
\hline 52 & -0.050 & -0.095 & 185.1 & -20.01 & 420.116 & 2005.842 & 468.714 & 78.247 & 606.857 \\
\hline 53 & -0.050 & -0.090 & 185.2 & -20.02 & 417.701 & 1994.311 & 461.693 & 77.348 & 618.801 \\
\hline 54 & -0.050 & -0.085 & 185.3 & -20.03 & 415.550 & 1984.041 & 455.046 & 76.507 & 630.843 \\
\hline 55 & -0.050 & -0.080 & 185.4 & -20.04 & 432.640 & 2065.642 & 469.351 & 79.196 & 672.517 \\
\hline 56 & -0.050 & -0.075 & 185.5 & -20.05 & 419.552 & 2003.151 & 450.910 & 76.360 & 667.301 \\
\hline 57 & -0.050 & -0.070 & 185.6 & -20.06 & 435.926 & 2081.327 & 464.136 & 78.886 & 708.939 \\
\hline
\end{tabular}


Table A1. Cont.

\begin{tabular}{|c|c|c|c|c|c|c|c|c|c|}
\hline Number & $\alpha_{i n}$ & $\alpha_{\text {out }}$ & $\beta_{o i l}$ & $\alpha_{o i l}$ & $\begin{array}{c}P \\
\mathbf{k W}\end{array}$ & $\begin{array}{c}N \\
\mathrm{Nm}\end{array}$ & $\underset{\mathbf{k W}}{Q}$ & $\begin{array}{c}P_{\text {mic }} \\
\text { bar }\end{array}$ & $\begin{array}{c}T_{m o} \\
\mathbf{K}\end{array}$ \\
\hline 58 & -0.050 & -0.065 & 185.7 & -20.07 & 429.338 & 2049.873 & 452.849 & 77.251 & 713.462 \\
\hline 59 & -0.050 & -0.060 & 185.8 & -20.08 & 427.195 & 2039.644 & 446.372 & 76.428 & 724.944 \\
\hline $60 *$ & -0.050 & -0.055 & 185.9 & -20.09 & 437.493 & 2088.808 & 452.847 & 77.826 & 757.700 \\
\hline 61 & -0.050 & -0.050 & 186.0 & -20.10 & 435.060 & 2077.195 & 446.102 & 76.954 & 768.566 \\
\hline 62 & -0.050 & -0.045 & 186.1 & -20.11 & 428.268 & 2044.764 & 441.714 & 75.825 & 743.148 \\
\hline 63 & -0.050 & -0.040 & 186.2 & -20.12 & 425.214 & 2030.183 & 441.150 & 75.357 & 724.381 \\
\hline 64 & -0.050 & -0.035 & 186.3 & -20.13 & 432.407 & 2064.525 & 451.271 & 76.707 & 722.789 \\
\hline 65 & -0.050 & -0.030 & 186.4 & -20.14 & 425.435 & 2031.241 & 446.640 & 75.544 & 697.364 \\
\hline 66 & -0.050 & -0.025 & 186.5 & -20.15 & 423.072 & 2019.958 & 446.818 & 75.200 & 679.643 \\
\hline 67 & -0.050 & -0.020 & 186.6 & -20.16 & 428.779 & 2047.204 & 455.570 & 76.291 & 674.620 \\
\hline 68 & -0.050 & -0.015 & 186.7 & -20.17 & 421.022 & 2010.170 & 450.034 & 74.987 & 648.327 \\
\hline 69 & -0.050 & -0.010 & 186.8 & -20.18 & 418.245 & 1996.911 & 449.784 & 74.568 & 629.896 \\
\hline 70 & -0.050 & -0.005 & 186.9 & -20.19 & 406.757 & 1942.063 & 440.103 & 72.595 & 598.673 \\
\hline 71 & -0.050 & 0.000 & 187.0 & -20.2 & 411.628 & 1965.316 & 448.109 & 73.542 & 591.593 \\
\hline $72 *$ & -0.050 & 0.005 & 187.1 & -20.16 & 414.409 & 1978.597 & 444.221 & 72.455 & 585.506 \\
\hline 73 & -0.050 & 0.010 & 187.2 & -20.12 & 436.443 & 2083.798 & 460.853 & 74.708 & 606.449 \\
\hline 74 & -0.050 & 0.015 & 187.3 & -20.08 & 432.215 & 2063.611 & 449.745 & 72.464 & 590.887 \\
\hline 75 & -0.050 & 0.020 & 187.4 & -20.04 & 442.358 & 2112.039 & 453.767 & 72.669 & 595.228 \\
\hline 76 & -0.050 & 0.025 & 187.5 & -20.00 & 452.735 & 2161.585 & 457.982 & 72.902 & 599.816 \\
\hline 77 & -0.050 & 0.030 & 187.6 & -19.96 & 459.834 & 2195.479 & 458.880 & 72.607 & 600.058 \\
\hline 78 & -0.050 & 0.035 & 187.7 & -19.92 & 468.496 & 2236.834 & 461.358 & 72.564 & 602.371 \\
\hline 79 & -0.050 & 0.040 & 187.8 & -19.88 & 478.888 & 2286.451 & 465.518 & 72.783 & 606.877 \\
\hline 80 & -0.050 & 0.045 & 187.9 & -19.84 & 485.888 & 2319.871 & 466.380 & 72.487 & 607.082 \\
\hline 81 & -0.050 & 0.050 & 188.0 & -19.8 & 499.071 & 2382.812 & 473.144 & 73.105 & 614.965 \\
\hline 82 & -0.050 & 0.055 & 187.6 & -19.81 & 494.763 & 2362.248 & 473.569 & 75.219 & 620.507 \\
\hline 83 & -0.050 & 0.060 & 187.2 & -19.82 & 494.081 & 2358.990 & 477.518 & 77.918 & 630.726 \\
\hline $84^{*}$ & -0.050 & 0.065 & 186.8 & -19.83 & 492.336 & 2350.660 & 480.521 & 80.498 & 639.783 \\
\hline 85 & -0.050 & 0.070 & 186.4 & -19.84 & 475.930 & 2272.328 & 469.145 & 80.638 & 629.620 \\
\hline 86 & -0.050 & 0.075 & 186.0 & -19.85 & 465.163 & 2220.918 & 463.166 & 81.636 & 626.530 \\
\hline 87 & -0.050 & 0.080 & 185.6 & -19.86 & 473.326 & 2259.893 & 476.121 & 86.008 & 649.140 \\
\hline 88 & -0.050 & 0.085 & 185.2 & -19.87 & 464.431 & 2217.427 & 472.021 & 87.343 & 648.607 \\
\hline 89 & -0.050 & 0.090 & 184.8 & -19.88 & 453.291 & 2164.238 & 465.543 & 88.198 & 644.705 \\
\hline 90 & -0.050 & 0.095 & 184.4 & -19.89 & 448.079 & 2139.356 & 465.094 & 90.169 & 649.094 \\
\hline 91 & -0.050 & 0.100 & 184.0 & -19.90 & 444.772 & 2123.565 & 466.648 & 92.540 & 656.302 \\
\hline 92 & -0.045 & 0.080 & 184.2 & -19.93 & 445.038 & 2124.835 & 467.741 & 91.481 & 658.338 \\
\hline 93 & -0.040 & 0.060 & 184.4 & -19.96 & 450.533 & 2151.072 & 474.345 & 91.476 & 668.139 \\
\hline 94 & -0.035 & 0.040 & 184.6 & -19.99 & 438.784 & 2094.975 & 462.786 & 87.980 & 652.351 \\
\hline 95 & -0.030 & 0.020 & 184.8 & -20.02 & 446.968 & 2134.050 & 472.249 & 88.484 & 666.195 \\
\hline 96 & -0.025 & 0.000 & 185.0 & -20.05 & 435.131 & 2077.532 & 460.555 & 85.028 & 650.192 \\
\hline 97 & -0.020 & -0.020 & 185.2 & -20.08 & 443.189 & 2116.005 & 469.916 & 85.464 & 663.912 \\
\hline $98 *$ & -0.015 & -0.040 & 185.4 & -20.11 & 428.283 & 2044.835 & 454.919 & 81.482 & 643.213 \\
\hline 99 & -0.010 & -0.060 & 185.6 & -20.14 & 443.389 & 2116.960 & 471.807 & 83.205 & 667.598 \\
\hline 100 & -0.005 & -0.080 & 185.8 & -20.17 & 435.256 & 2078.129 & 463.983 & 80.542 & 657.028 \\
\hline 101 & 0.000 & -0.100 & 186.0 & -20.20 & 433.272 & 2068.658 & 462.699 & 79.037 & 655.711 \\
\hline 102 & 0.000 & -0.095 & 186.1 & -20.16 & 438.555 & 2093.882 & 458.243 & 79.003 & 652.932 \\
\hline 103 & 0.000 & -0.090 & 186.2 & -20.12 & 446.871 & 2133.586 & 456.984 & 79.518 & 654.697 \\
\hline 104 & 0.000 & -0.085 & 186.3 & -20.08 & 448.202 & 2139.939 & 448.691 & 78.800 & 646.346 \\
\hline 105 & 0.000 & -0.080 & 186.4 & -20.04 & 462.791 & 2209.595 & 453.648 & 80.412 & 657.090 \\
\hline 106 & 0.000 & -0.075 & 186.5 & -20.00 & 465.942 & 2224.642 & 447.330 & 80.030 & 651.527 \\
\hline 107 & 0.000 & -0.070 & 186.6 & -19.96 & 473.533 & 2260.882 & 445.353 & 80.418 & 652.256 \\
\hline 108 & 0.000 & -0.065 & 186.7 & -19.92 & 477.424 & 2279.462 & 439.958 & 80.184 & 647.954 \\
\hline 109 & 0.000 & -0.060 & 186.8 & -19.88 & 485.096 & 2316.091 & 438.105 & 80.591 & 648.845 \\
\hline $110 *$ & 0.000 & -0.055 & 186.9 & -19.84 & 507.266 & 2421.943 & 449.073 & 83.379 & 668.839 \\
\hline 111 & 0.000 & -0.050 & 187.0 & -19.8 & 507.444 & 2422.792 & 440.439 & 82.539 & 659.692 \\
\hline 112 & 0.000 & -0.045 & 187.1 & -19.81 & 502.758 & 2400.418 & 443.057 & 83.043 & 658.460 \\
\hline 113 & 0.000 & -0.040 & 187.2 & -19.82 & 501.649 & 2395.121 & 448.936 & 84.157 & 661.993 \\
\hline 114 & 0.000 & -0.035 & 187.3 & -19.83 & 477.620 & 2280.398 & 434.147 & 81.397 & 635.166 \\
\hline 115 & 0.000 & -0.030 & 187.4 & -19.84 & 485.300 & 2317.065 & 448.147 & 84.035 & 650.483 \\
\hline 116 & 0.000 & -0.025 & 187.5 & -19.85 & 477.677 & 2280.670 & 448.218 & 84.061 & 645.435 \\
\hline
\end{tabular}


Table A1. Cont.

\begin{tabular}{|c|c|c|c|c|c|c|c|c|c|}
\hline Number & $\alpha_{i n}$ & $\alpha_{\text {out }}$ & $\beta_{o i l}$ & $\alpha_{o i l}$ & $\begin{array}{c}P \\
\mathbf{k W}\end{array}$ & $\begin{array}{c}N \\
\mathrm{Nm}\end{array}$ & $\underset{\mathbf{k W}}{Q}$ & $\begin{array}{c}P_{\text {mic }} \\
\text { bar }\end{array}$ & $\begin{array}{c}T_{m o} \\
\mathbf{K}\end{array}$ \\
\hline 117 & 0.000 & -0.020 & 187.6 & -19.86 & 471.945 & 2253.301 & 450.073 & 84.422 & 642.949 \\
\hline 118 & 0.000 & -0.015 & 187.7 & -19.87 & 450.064 & 2148.829 & 436.312 & 81.853 & 618.306 \\
\hline 119 & 0.000 & -0.010 & 187.8 & -19.88 & 446.239 & 2130.566 & 439.865 & 82.531 & 618.330 \\
\hline 120 & 0.000 & -0.005 & 187.9 & -19.89 & 444.939 & 2124.359 & 446.048 & 83.704 & 621.956 \\
\hline 121 & 0.000 & 0.000 & 188.0 & -19.90 & 438.336 & 2092.835 & 447.014 & 83.898 & 618.242 \\
\hline $122 *$ & 0.000 & 0.005 & 187.6 & -19.91 & 441.460 & 2107.748 & 450.789 & 85.038 & 626.993 \\
\hline 123 & 0.000 & 0.010 & 187.2 & -19.92 & 429.012 & 2048.320 & 438.652 & 83.168 & 613.551 \\
\hline 124 & 0.000 & 0.015 & 186.8 & -19.93 & 437.432 & 2088.519 & 447.848 & 85.340 & 629.924 \\
\hline 125 & 0.000 & 0.020 & 186.4 & -19.94 & 442.048 & 2110.558 & 453.169 & 86.788 & 640.962 \\
\hline 126 & 0.000 & 0.025 & 186.0 & -19.95 & 436.067 & 2082.000 & 447.625 & 86.155 & 636.633 \\
\hline 127 & 0.000 & 0.030 & 185.6 & -19.96 & 437.838 & 2090.458 & 450.036 & 87.050 & 643.593 \\
\hline 128 & 0.000 & 0.035 & 185.2 & -19.97 & 433.071 & 2067.699 & 445.725 & 86.644 & 640.926 \\
\hline 129 & 0.000 & 0.040 & 184.8 & -19.98 & 437.087 & 2086.874 & 450.453 & 87.995 & 651.263 \\
\hline 130 & 0.000 & 0.045 & 184.4 & -19.99 & 439.796 & 2099.807 & 453.845 & 89.093 & 659.732 \\
\hline 131 & 0.000 & 0.050 & 184.0 & -20.00 & 431.890 & 2062.058 & 446.278 & 88.036 & 652.239 \\
\hline 132 & 0.000 & 0.055 & 184.1 & -20.01 & 432.261 & 2063.832 & 447.258 & 87.894 & 657.045 \\
\hline 133 & 0.000 & 0.060 & 184.2 & -20.02 & 432.100 & 2063.064 & 447.686 & 87.644 & 661.040 \\
\hline 134 & 0.000 & 0.065 & 184.3 & -20.03 & 437.175 & 2087.291 & 453.545 & 88.454 & 673.088 \\
\hline $135 *$ & 0.000 & 0.070 & 184.4 & -20.04 & 430.908 & 2057.369 & 447.636 & 86.970 & 667.659 \\
\hline 136 & 0.000 & 0.075 & 184.5 & -20.05 & 441.041 & 2105.752 & 458.769 & 88.795 & 687.675 \\
\hline 137 & 0.000 & 0.080 & 184.6 & -20.06 & 440.570 & 2103.503 & 458.883 & 88.480 & 691.247 \\
\hline 138 & 0.000 & 0.085 & 184.7 & -20.07 & 428.063 & 2043.787 & 446.443 & 85.754 & 675.803 \\
\hline 139 & 0.000 & 0.090 & 184.8 & -20.08 & 429.063 & 2048.560 & 448.073 & 85.740 & 681.567 \\
\hline 140 & 0.000 & 0.095 & 184.9 & -20.09 & 441.691 & 2108.853 & 461.865 & 88.044 & 705.931 \\
\hline 141 & 0.000 & 0.100 & 185.0 & -20.10 & 433.986 & 2072.067 & 454.402 & 86.292 & 697.843 \\
\hline 142 & 0.005 & 0.080 & 185.2 & -20.08 & 433.094 & 2067.809 & 453.495 & 84.840 & 689.066 \\
\hline 143 & 0.010 & 0.060 & 185.4 & -20.06 & 429.127 & 2048.867 & 449.368 & 82.801 & 675.478 \\
\hline 144 & 0.015 & 0.040 & 185.6 & -20.04 & 438.779 & 2094.952 & 459.504 & 83.372 & 683.230 \\
\hline 145 & 0.020 & 0.020 & 185.8 & -20.02 & 429.856 & 2052.345 & 450.186 & 80.412 & 662.044 \\
\hline $146 *$ & 0.025 & 0.000 & 186.0 & -20.00 & 432.012 & 2062.639 & 452.471 & 79.543 & 658.036 \\
\hline 147 & 0.030 & -0.020 & 186.2 & -19.98 & 432.260 & 2063.823 & 452.759 & 78.317 & 651.080 \\
\hline 148 & 0.035 & -0.040 & 186.4 & -19.96 & 427.376 & 2040.505 & 447.671 & 76.173 & 636.471 \\
\hline 149 & 0.040 & -0.060 & 186.6 & -19.94 & 433.600 & 2070.224 & 454.218 & 76.006 & 638.382 \\
\hline 150 & 0.045 & -0.080 & 186.8 & -19.92 & 427.689 & 2042.001 & 448.053 & 73.710 & 622.419 \\
\hline 151 & 0.050 & -0.100 & 187.0 & -19.90 & 433.639 & 2070.409 & 454.314 & 73.458 & 623.716 \\
\hline 152 & 0.050 & -0.095 & 187.1 & -19.91 & 434.673 & 2075.345 & 454.106 & 74.465 & 630.109 \\
\hline 153 & 0.050 & -0.090 & 187.2 & -19.92 & 439.307 & 2097.469 & 457.644 & 76.097 & 641.778 \\
\hline 154 & 0.050 & -0.085 & 187.3 & -19.93 & 441.766 & 2109.212 & 458.897 & 77.366 & 650.343 \\
\hline 155 & 0.050 & -0.080 & 187.4 & -19.94 & 428.543 & 2046.077 & 443.893 & 75.866 & 635.694 \\
\hline 156 & 0.050 & -0.075 & 187.5 & -19.95 & 427.125 & 2039.308 & 441.163 & 76.427 & 638.386 \\
\hline 157 & 0.050 & -0.070 & 187.6 & -19.96 & 429.764 & 2051.909 & 442.621 & 77.716 & 647.148 \\
\hline $158 *$ & 0.050 & -0.065 & 187.7 & -19.97 & 428.579 & 2046.251 & 440.137 & 78.314 & 650.162 \\
\hline 159 & 0.050 & -0.060 & 187.8 & -19.98 & 434.792 & 2075.916 & 445.239 & 80.273 & 664.449 \\
\hline 160 & 0.050 & -0.055 & 187.9 & -19.99 & 439.951 & 2100.546 & 449.228 & 82.058 & 677.245 \\
\hline 161 & 0.050 & -0.050 & 188.0 & -20.00 & 436.549 & 2084.302 & 444.473 & 82.248 & 676.876 \\
\hline 162 & 0.050 & -0.045 & 187.6 & -20.01 & 436.311 & 2083.169 & 445.624 & 83.355 & 674.778 \\
\hline 163 & 0.050 & -0.040 & 187.2 & -20.02 & 446.239 & 2130.567 & 457.184 & 86.425 & 688.369 \\
\hline 164 & 0.050 & -0.035 & 186.8 & -20.03 & 441.326 & 2107.113 & 453.550 & 86.631 & 679.053 \\
\hline 165 & 0.050 & -0.030 & 186.4 & -20.04 & 440.192 & 2101.696 & 453.776 & 87.558 & 675.580 \\
\hline 166 & 0.050 & -0.025 & 186.0 & -20.05 & 437.098 & 2086.924 & 451.963 & 88.081 & 669.122 \\
\hline 167 & 0.050 & -0.020 & 185.6 & -20.06 & 448.304 & 2140.429 & 464.958 & 91.503 & 684.530 \\
\hline 168 & 0.050 & -0.015 & 185.2 & -20.07 & 434.778 & 2075.848 & 452.290 & 89.867 & 662.187 \\
\hline 169 & 0.050 & -0.010 & 184.8 & -20.08 & 450.738 & 2152.051 & 470.299 & 94.329 & 684.750 \\
\hline $170 *$ & 0.050 & -0.005 & 184.4 & -20.09 & 440.920 & 2105.172 & 461.425 & 93.407 & 668.132 \\
\hline 171 & 0.050 & 0.000 & 184.0 & -20.10 & 443.854 & 2119.180 & 465.871 & 95.166 & 670.871 \\
\hline 172 & 0.050 & 0.005 & 184.1 & -20.11 & 441.862 & 2109.672 & 468.230 & 93.229 & 670.283 \\
\hline 173 & 0.050 & 0.010 & 184.2 & -20.12 & 439.624 & 2098.986 & 470.354 & 91.232 & 669.335 \\
\hline 174 & 0.050 & 0.015 & 184.3 & -20.13 & 434.976 & 2076.791 & 469.899 & 88.734 & 664.716 \\
\hline 175 & 0.050 & 0.020 & 184.4 & -20.14 & 435.351 & 2078.585 & 474.899 & 87.252 & 667.792 \\
\hline
\end{tabular}


Table A1. Cont.

\begin{tabular}{|c|c|c|c|c|c|c|c|c|c|}
\hline Number & $\alpha_{i n}$ & $\alpha_{\text {out }}$ & $\beta_{o i l}$ & $\alpha_{o i l}$ & $\begin{array}{c}P \\
\mathbf{k W}\end{array}$ & $\begin{array}{c}N \\
\text { Nm }\end{array}$ & $\underset{\mathbf{k W}}{Q}$ & $\begin{array}{c}P_{\text {mic }} \\
\text { bar }\end{array}$ & $\begin{array}{c}T_{m o} \\
\mathbf{K}\end{array}$ \\
\hline 176 & 0.050 & 0.025 & 184.5 & -20.15 & 425.565 & 2031.862 & 468.787 & 83.743 & 655.264 \\
\hline 177 & 0.050 & 0.030 & 184.6 & -20.16 & 419.156 & 2001.263 & 466.294 & 80.932 & 647.882 \\
\hline 178 & 0.050 & 0.035 & 184.7 & -20.17 & 421.140 & 2010.734 & 473.164 & 79.733 & 653.487 \\
\hline 179 & 0.050 & 0.040 & 184.8 & -20.18 & 422.307 & 2016.303 & 479.227 & 78.342 & 657.884 \\
\hline 180 & 0.050 & 0.045 & 184.9 & -20.19 & 417.043 & 1991.172 & 478.025 & 75.747 & 652.281 \\
\hline 181 & 0.050 & 0.050 & 185.0 & -20.20 & 409.677 & 1956.001 & 474.346 & 72.792 & 643.354 \\
\hline $182 *$ & 0.050 & 0.055 & 185.1 & -20.16 & 422.704 & 2018.201 & 474.331 & 74.228 & 644.324 \\
\hline 183 & 0.050 & 0.060 & 185.2 & -20.12 & 426.643 & 2037.008 & 464.304 & 74.079 & 631.683 \\
\hline 184 & 0.050 & 0.065 & 185.3 & -20.08 & 445.843 & 2128.680 & 470.868 & 76.578 & 641.615 \\
\hline 185 & 0.050 & 0.070 & 185.4 & -20.04 & 448.249 & 2140.165 & 459.714 & 76.194 & 627.402 \\
\hline 186 & 0.050 & 0.075 & 185.5 & -20.00 & 472.337 & 2255.173 & 470.685 & 79.489 & 643.393 \\
\hline 187 & 0.050 & 0.080 & 185.6 & -19.96 & 484.904 & 2315.175 & 469.774 & 80.822 & 643.173 \\
\hline 188 & 0.050 & 0.085 & 185.7 & -19.92 & 481.593 & 2299.364 & 453.838 & 79.529 & 622.354 \\
\hline 189 & 0.050 & 0.090 & 185.8 & -19.88 & 502.060 & 2397.086 & 460.455 & 82.171 & 632.450 \\
\hline 190 & 0.050 & 0.095 & 185.9 & -19.84 & 509.058 & 2430.499 & 454.592 & 82.601 & 625.415 \\
\hline 191 & 0.050 & 0.100 & 186.0 & -19.80 & 522.206 & 2493.273 & 454.277 & 84.033 & 626.009 \\
\hline 192 & 0.055 & 0.080 & 186.2 & -19.83 & 515.216 & 2459.900 & 456.973 & 84.186 & 633.892 \\
\hline 193 & 0.060 & 0.060 & 186.4 & -19.86 & 495.097 & 2363.842 & 447.887 & 82.174 & 625.371 \\
\hline $194^{*}$ & 0.065 & 0.040 & 186.6 & -19.89 & 497.580 & 2375.697 & 459.283 & 83.918 & 645.462 \\
\hline 195 & 0.070 & 0.020 & 186.8 & -19.92 & 489.354 & 2336.423 & 461.051 & 83.893 & 652.136 \\
\hline 196 & 0.075 & 0.000 & 187.0 & -19.95 & 469.128 & 2239.852 & 451.336 & 81.786 & 642.492 \\
\hline 197 & 0.080 & -0.020 & 187.2 & -19.98 & 457.320 & 2183.476 & 449.463 & 81.109 & 643.901 \\
\hline 198 & 0.085 & -0.040 & 187.4 & -20.01 & 455.046 & 2172.618 & 457.072 & 82.139 & 658.939 \\
\hline 199 & 0.090 & -0.060 & 187.6 & -20.04 & 435.982 & 2081.596 & 447.766 & 80.130 & 649.573 \\
\hline 200 & 0.095 & -0.080 & 187.8 & -20.07 & 429.609 & 2051.167 & 451.353 & 80.434 & 658.853 \\
\hline 201 & 0.100 & -0.100 & 188.0 & -20.10 & 425.114 & 2029.706 & 457.115 & 81.119 & 671.388 \\
\hline 202 & 0.100 & -0.095 & 187.6 & -20.11 & 425.553 & 2031.803 & 458.094 & 82.278 & 679.348 \\
\hline 203 & 0.100 & -0.090 & 187.2 & -20.12 & 428.094 & 2043.934 & 461.343 & 83.859 & 690.766 \\
\hline 204 & 0.100 & -0.085 & 186.8 & -20.13 & 419.525 & 2003.024 & 452.616 & 83.256 & 684.205 \\
\hline 205 & 0.100 & -0.080 & 186.4 & -20.14 & 424.794 & 2028.180 & 458.817 & 85.398 & 700.208 \\
\hline $206^{*}$ & 0.100 & -0.075 & 186.0 & -20.15 & 413.241 & 1973.021 & 446.846 & 84.150 & 688.425 \\
\hline 207 & 0.100 & -0.070 & 185.6 & -20.16 & 417.281 & 1992.308 & 451.729 & 86.065 & 702.539 \\
\hline 208 & 0.100 & -0.065 & 185.2 & -20.17 & 418.252 & 1996.946 & 453.301 & 87.369 & 711.629 \\
\hline 209 & 0.100 & -0.060 & 184.8 & -20.18 & 409.455 & 1954.945 & 444.280 & 86.619 & 704.013 \\
\hline 210 & 0.100 & -0.055 & 184.4 & -20.19 & 411.802 & 1966.147 & 447.345 & 88.217 & 715.494 \\
\hline 211 & 0.100 & -0.050 & 184.0 & -20.20 & 410.100 & 1958.022 & 446.018 & 88.958 & 720.008 \\
\hline 212 & 0.100 & -0.045 & 184.1 & -20.16 & 417.385 & 1992.804 & 445.067 & 87.532 & 703.968 \\
\hline 213 & 0.100 & -0.040 & 184.2 & -20.12 & 426.837 & 2037.933 & 446.519 & 86.591 & 691.882 \\
\hline 214 & 0.100 & -0.035 & 184.3 & -20.08 & 435.874 & 2081.079 & 447.588 & 85.583 & 679.288 \\
\hline 215 & 0.100 & -0.030 & 184.4 & -20.04 & 451.615 & 2156.238 & 455.473 & 85.869 & 676.921 \\
\hline 216 & 0.100 & -0.025 & 184.5 & -20.00 & 457.493 & 2184.302 & 453.400 & 84.275 & 659.735 \\
\hline $217 *$ & 0.100 & -0.020 & 184.6 & -19.96 & 481.972 & 2301.173 & 469.608 & 86.057 & 668.876 \\
\hline 218 & 0.100 & -0.015 & 184.7 & -19.92 & 483.110 & 2306.608 & 463.001 & 83.646 & 645.388 \\
\hline 219 & 0.100 & -0.010 & 184.8 & -19.88 & 488.974 & 2334.607 & 461.148 & 82.129 & 628.941 \\
\hline 220 & 0.100 & -0.005 & 184.9 & -19.84 & 509.723 & 2433.673 & 473.253 & 83.085 & 631.383 \\
\hline 221 & 0.100 & 0.000 & 185.0 & -19.80 & 516.548 & 2466.257 & 472.338 & 81.741 & 616.278 \\
\hline 222 & 0.100 & 0.005 & 185.1 & -19.81 & 511.380 & 2441.583 & 473.848 & 81.457 & 617.829 \\
\hline 223 & 0.100 & 0.010 & 185.2 & -19.82 & 494.387 & 2360.451 & 464.296 & 79.280 & 604.965 \\
\hline 224 & 0.100 & 0.015 & 185.3 & -19.83 & 504.046 & 2406.566 & 479.858 & 81.384 & 624.818 \\
\hline 225 & 0.100 & 0.020 & 185.4 & -19.84 & 495.208 & 2364.370 & 478.002 & 80.518 & 621.979 \\
\hline 226 & 0.100 & 0.025 & 185.5 & -19.85 & 476.074 & 2273.013 & 466.018 & 77.962 & 605.973 \\
\hline 227 & 0.100 & 0.030 & 185.6 & -19.86 & 481.002 & 2296.544 & 477.585 & 79.346 & 620.591 \\
\hline 228 & 0.100 & 0.035 & 185.7 & -19.87 & 460.046 & 2196.490 & 463.417 & 76.457 & 601.772 \\
\hline $229 *$ & 0.100 & 0.040 & 185.8 & -19.88 & 469.805 & 2243.085 & 480.232 & 78.676 & 623.181 \\
\hline 230 & 0.100 & 0.045 & 185.9 & -19.89 & 455.612 & 2175.321 & 472.703 & 76.897 & 612.992 \\
\hline 231 & 0.100 & 0.050 & 186.0 & -19.90 & 447.409 & 2136.156 & 471.257 & 76.117 & 610.700 \\
\hline 232 & 0.100 & 0.055 & 186.1 & -19.91 & 451.170 & 2154.112 & 476.258 & 77.807 & 623.612 \\
\hline 233 & 0.100 & 0.060 & 186.2 & -19.92 & 437.730 & 2089.940 & 463.092 & 76.523 & 612.683 \\
\hline 234 & 0.100 & 0.065 & 186.3 & -19.93 & 435.036 & 2077.077 & 461.272 & 77.093 & 616.617 \\
\hline
\end{tabular}


Table A1. Cont.

\begin{tabular}{cccccccccc}
\hline Number & $\boldsymbol{\alpha}_{\text {in }}$ & $\boldsymbol{\alpha}_{\text {out }}$ & $\boldsymbol{\beta}_{\text {oil }}$ & $\boldsymbol{\alpha}_{\text {oil }}$ & $\begin{array}{c}\boldsymbol{P} \\
\mathbf{k W}\end{array}$ & $\begin{array}{c}\boldsymbol{N} \\
\mathbf{N m}\end{array}$ & $\begin{array}{c}\boldsymbol{Q} \\
\mathbf{k W}\end{array}$ & $\begin{array}{c}\boldsymbol{P}_{\text {mic }} \\
\text { bar }\end{array}$ & $\begin{array}{c}\boldsymbol{T}_{\text {mo }} \\
\mathbf{K}\end{array}$ \\
\hline 235 & 0.100 & 0.070 & 186.4 & -19.94 & 436.906 & 2086.006 & 464.303 & 78.484 & 627.111 \\
236 & 0.100 & 0.075 & 186.5 & -19.95 & 438.642 & 2094.295 & 467.215 & 79.874 & 637.585 \\
237 & 0.100 & 0.080 & 186.6 & -19.96 & 421.193 & 2010.988 & 449.669 & 77.747 & 619.994 \\
$238^{*}$ & 0.100 & 0.085 & 186.7 & -19.97 & 418.885 & 1999.968 & 448.252 & 78.380 & 624.433 \\
239 & 0.100 & 0.090 & 186.8 & -19.98 & 432.048 & 2062.814 & 463.433 & 81.950 & 652.251 \\
240 & 0.100 & 0.095 & 186.9 & -19.99 & 428.435 & 2045.561 & 460.659 & 82.378 & 655.037 \\
241 & 0.100 & 0.100 & 187.0 & -20.00 & 417.703 & 1994.322 & 450.209 & 81.416 & 646.779 \\
\hline
\end{tabular}

Note: Superscript * indicates that this sample is the verification data.

\section{References}

1. Zhu, Z.; Zhang, F.; Li, C.; Wu, T.; Han, K.; Lv, J.; Li, Y.; Xiao, X. Genetic algorithm optimization applied to the fuel supply parameters of diesel engines working at plateau. Appl. Energy 2015, 157, 789-797. [CrossRef]

2. Huaiqing, Z. Research on Power Enhancement of 16V280ZJA Diesel Engine for Plateau Locomotive. Master's Thesis, Shanghai Jiaotong University, Shanghai, China, 2007.

3. Qiangqiang, T.; Deyuan, W.; Chengguan, W.; Yuan, L.; Diming, L.; Yunguang, L.; Sheng, L.; Zhenhuan, Y. Research on Performance Optimization of Heavy-duty Diesel Engines in Plateau Environment. Ordnance Ind. 2018, 39, 436-443.

4. Zhang, H.; Zhang, H.; Wang, Z. Effect on Vehicle Turbocharger Exhaust Gas Energy Utilization for the Performance of Centrifugal Compressors under Plateau Conditions. Energies 2017, 10, 2121. [CrossRef]

5. Xia, M.; Zhao, C.; Zhang, F.; Huang, Y. Modeling the Performance of a New Speed Adjustable Compound Supercharging Diesel Engine Working under Plateau Conditions. Energies 2017, 10, 689.

6. Qiao, Y.; Lyu, G.; Song, C.; Liang, X.; Zhang, H.; Dong, D. Optimization of Programmed Temperature Vaporization Injection for Determination of Polycyclic Aromatic Hydrocarbons from Diesel Combustion Process. Energies 2019, 12, 4791. [CrossRef]

7. Cococcetta, F.; Finesso, R.; Hardy, G.; Marello, O.; Spessa, E. Implementation and Assessment of a Model-Based Controller of Torque and Nitrogen Oxide Emissions in an 11 L Heavy-Duty Diesel Engine. Energies 2019, 12, 4704. [CrossRef]

8. Markov, V.; Kamaltdinov, V.; Zherdev, A.; Furman, V.; Sa, B.; Neverov, V. Study on the Possibility of Improving the Environmental Performance of Diesel Engine Using Carbon Nanotubes as a Petroleum Diesel Fuel Additive. Energies 2019, 12, 4345. [CrossRef]

9. Nand Agrawal, B.; Sinha, S.; Bandhu Singh, D.; Bansal, G. Effects of blends of castor oil with pure diesel on performance parameters of direct injection compression ignition engine. Mater. Today Proc. 2019, in press. [CrossRef]

10. d'Ambrosio, S.; Ferrari, A.; Mancarella, A.; Mancò, S.; Mittica, A. Comparison of the Emissions, Noise, and Fuel Consumption Comparison of Direct and Indirect Piezoelectric and Solenoid Injectors in a Low-Compression-Ratio Diesel Engine. Energies 2019, 12, 4023. [CrossRef]

11. Wong, K.I.; Wong, P.K.; Cheung, C.S.; Vong, C.M. Modeling and optimization of biodiesel engine performance using advanced machine learning methods. Energy 2013, 55, 519-528. [CrossRef]

12. Zhao, J.; Xu, M. Fuel economy optimization of an Atkinson cycle engine using genetic algorithm. Appl. Energy 2013, 105, 335-348. [CrossRef]

13. Yoo, H.; Park, B.Y.; Cho, H.; Park, J. Performance Optimization of a Diesel Engine with a Two-Stage Turbocharging System and Dual-Loop EGR Using Multi-Objective Pareto Optimization Based on Diesel Cycle Simulation. Energies 2019, 12, 4223. [CrossRef]

14. Bietresato, M.; Caligiuri, C.; Bolla, A.; Renzi, M.; Mazzetto, F. Proposal of a Predictive Mixed Experimental-Numerical Approach for Assessing the Performance of Farm Tractor Engines Fuelled with Diesel-Biodiesel-Bioethanol Blends. Energies 2019, 12, 2287. [CrossRef]

15. Najafi, B.; Faizollahzadeh Ardabili, S.; Mosavi, A.; Shamshirband, S.; Rabczuk, T. An Intelligent Artificial Neural Network-Response Surface Methodology Method for Accessing the Optimum Biodiesel and Diesel Fuel Blending Conditions in a Diesel Engine from the Viewpoint of Exergy and Energy Analysis. Energies 2018, 11, 860. [CrossRef] 
16. Li, Z.; Li, Y.; Li, Y. Performance Evaluation of Energy Transition Based on the Technique for Order Preference by a Similar to Ideal Solution and Support Vector Machine Optimized by an Improved Artificial Bee Colony Algorithm. Energies 2019, 12, 3059. [CrossRef]

17. García Álvarez, J.; González, M.Á.; Rodríguez Vela, C.; Varela, R. Electric Vehicle Charging Scheduling by an Enhanced Artificial Bee Colony Algorithm. Energies 2018, 11, 2752. [CrossRef]

18. Tan, S.; Wang, X.; Jiang, C. Privacy-Preserving Energy Scheduling for ESCOs Based on Energy Blockchain Network. Energies 2019, 12, 1530. [CrossRef]

19. Jamaluddin, K.; Wan Alwi, S.R.; Abdul Manan, Z.; Hamzah, K.; Klemeš, J.J. A Process Integration Method for Total Site Cooling, Heating and Power Optimisation with Trigeneration Systems. Energies 2019, $12,1030$. [CrossRef]

20. Marti-Puig, P.; Blanco-M, A.; Cárdenas, J.J.; Cusidó, J.; Solé-Casals, J. Feature Selection Algorithms for Wind Turbine Failure Prediction. Energies 2019, 12, 453. [CrossRef]

21. Jiao, Y.; Liu, R.; Zhang, Z.; Yang, C.; Zhou, G.; Dong, S.; Liu, W. Comparison of combustion and emission characteristics of a diesel engine fueled with diesel and methanol-Fischer-Tropsch diesel-biodiesel-diesel blends at various altitudes. Fuel 2019, 243, 52-59. [CrossRef]

22. Kan, Z.; Hu, Z.; Lou, D.; Tan, P.; Cao, Z.; Yang, Z. Effects of altitude on combustion and ignition characteristics of speed-up period during cold start in a diesel engine. Energy 2018, 150, 164-175. [CrossRef]

23. Li, M.; Lu, S.; Chen, R.; Guo, J.; Wang, C. Experimental investigation on flame spread over diesel fuel near sea level and at high altitude. Fuel 2016, 184, 665-671. [CrossRef]

24. Karataş, A.E.; Gülder, Ö.L. Soot formation in high pressure laminar diffusion flames. Prog. Energy Combust. Sci. 2012, 38, 818-845. [CrossRef]

25. Zhou, Y.; Huang, X.; Peng, S.; Li, L. Comparative study on the combustion characteristics of an atmospheric induction stove in the plateau and plain regions of China. Appl. Therm. Eng. 2017, 111, 301-307. [CrossRef]

26. El Shenawy, E.A.; Elkelawy, M.; Bastawissi, H.A.-E.; Panchal, H.; Shams, M.M. Comparative study of the combustion, performance, and emission characteristics of a direct injection diesel engine with a partially premixed lean charge compression ignition diesel engines. Fuel 2019, 249, 277-285. [CrossRef]

27. Giraldo, M.; Huertas, J.I. Real emissions, driving patterns and fuel consumption of in-use diesel buses operating at high altitude. Transp. Res. Part D Transp. Environ. 2019, 77, 21-36. [CrossRef]

28. Zhang, H.; Shi, L.; Deng, K.; Liu, S.; Yang, Z. Experiment investigation on the performance and regulation rule of two-stage turbocharged diesel engine for various altitudes operation. Energy 2020, 192, 116653. [CrossRef]

29. Yang, M.; Gu, Y.; Deng, K.; Yang, Z.; Zhang, Y. Analysis on altitude adaptability of turbocharging systems for a heavy-duty diesel engine. Appl. Therm. Eng. 2018, 128, 1196-1207. [CrossRef]

30. Wang, X.; Guo, M.; He, M.; Gu, C.; Cheng, J. Study on improvement of high power diesel engine performance in plateau environment. Chin. Intern. Combust. Engine Eng. 2014, 35, 113-118. (In Chinese)

31. Xin, Q. Diesel Engine System Design; Elsevier: Amsterdam, The Netherlands, 2011.

32. Menezes, M.V.F.; Torres, L.C.B.; Braga, A.P. Width optimization of RBF kernels for binary classification of support vector machines: A density estimation-based approach. Pattern Recognit. Lett. 2019, 128, 1-7. [CrossRef]

33. Zhu, Z.X.; Zhang, F.J.; Li, C.J.; Han, K. Calibration for Fuel Injection Parameters of the Diesel Engine Working at Plateau via Simulating. Adv. Mech. Eng. 2015, 6, 621946. [CrossRef]

34. Belgiorno, G.; Di Blasio, G.; Beatrice, C. Parametric study and optimization of the main engine calibration parameters and compression ratio of a methane-diesel dual fuel engine. Fuel 2018, 222, 821-840. [CrossRef]

(C) 2020 by the authors. Licensee MDPI, Basel, Switzerland. This article is an open access article distributed under the terms and conditions of the Creative Commons Attribution (CC BY) license (http://creativecommons.org/licenses/by/4.0/). 